\title{
LA MONEDA DINÁSTICA EN EL OCASO \\ DEL IMPERIO BIZANTINO. \\ DUCAS-ANGEL, COMNENOS Y PALEÓLOGOS
}

\author{
THE DINASTIC COIN IN THE DECLINE \\ IN THE BYZANTINE EMPIRE. \\ DUCAS-ANGELO, COMNENOS AND PALEOLOGUES
}

\author{
José María De Francisco Olmos \\ Universidad Complutense de Madrid
}

Resumen: En este artículo se analiza el problema de la sucesión al trono en el Imperio Bizantino desde el siglo XI hasta el XV, donde se aprecia la fuerza de la idea dinástica frente a la sucesión providencial, aunque ésta sigue muy viva, como puede verse en el acceso al trono de Miguel VIII, que justificaba sus actos y el cambo dinástico apoyándose en ella. Veremos como en el siglo XI se mantienen las asociaciones en las monedas y los emperadores que llegan al trono por matrimonio (Romano IV) mantienen el derecho sucesorio de los hijos de su antecesor. La llegada de una nueva dinastía está marcada por la relación con la divinidad que asegura su continuidad, como vemos con los Comneno y los Paleólogos. Estos últimos consiguen consolidarse y resistir cualquier intento de usurpación de otros pretendientes al trono (Cantacuzeno).

Palabras clave: Bizancio, Sucesión al Trono, siglos XI-XV, Ducas-Angelo, Comnenos, Paleólogos, Moneda dinástica, Montferrato.

Abstract: In this article we analyze the question of throne succession in the Byzantine Empire from the $11^{\text {th }}$ to the $15^{\text {th }}$ century, where the idea of dynastical succession advances to the detriment of the providential succession, although the latter is still quite strong, as can be seen in Michel VIII's accession, who justified his enthronement appealing to it. It will be shown how in the $9^{\text {th }}$ century associations are kept in the coins, and the emperors reach the throne through marriage and manage to keep the succession rights their his sons. The accession of a new dynasty is characterised by its relation to the divinity that grants its continuity, as happened with the Komnenoi and the Palaeologi. The latter managed to consolidate and resist any usurpation attempt from other pretenders to the throne, that always had to look for some ties to the throne to be accepted (for instance the Kantakouzenoi).

Keywords: Byzance, Succession to the throne XI-XV Century, Ducas-Angelo, Comnenos, Paleologues, Dinastic coins, Montferrate.

\section{INTRODUCCIÓN}

El Imperio Bizantino tenía como el principal de sus problemas el de la sucesión al trono, que no podía regularse por ser el Imperio regido por la Providencia Divina, las primeras dinastías, la 
Casa de Justino y los Heraclidas avanzaron en su intento de forzar soluciones dinásticas, en especial a través de las adopciones y asociaciones al trono ${ }^{1}$, pero será en los siglos siguientes cuando se afianzará el concepto dinástico del trono y los veremos en las acuñaciones monetarias de los Isaurios, Amorianos y sobre todo de los Macedonios ${ }^{2}$. Con estos precedentes pasaremos ahora a ver como se desarrolla el tema de la sucesión y su reflejo en la moneda en los últimos siglos de Bizancio, primero con las grandes reformas de los siglos XI y XII, luego con el exilio a Nicea tras la caída de Constantinopla en poder de los latinos pertenecientes a la Cuarta Cruzada, y por fin los problemas que tuvo para mantenerse en el poder la última de las grandes dinastías bizantinas, los Paleólogos.

\section{LOS DUCAS-COMNENO-ANGEL}

El concepto dinástico en Bizancio ya estaba fijado, de hecho se había consolidado de forma extraordinaria en época de los Macedonios, pero el ejercicio del poder seguía teniendo cierta inestabilidad, por una parte por la permanencia de la idea providencialista y por otra por la inexistencia de un claro sistema sucesorio, lo que facilitaba las "usurpaciones" temporales y engendraba graves discordias en el seno de la familia imperial reinante, ya que la sola voluntad del emperador era la que podía imponer a uno u otro candidato. De hecho, en Bizancio, desde el siglo XI al XV, el heredero designado, aunque estuviera asociado ya en el gobierno, casi siempre se veía obligado a respaldar sus derechos por la fuerza o pactando su reconocimiento con el Senado, el ejército o el poderoso Patriarca de Constantinopla (cabeza de la Iglesia Ortodoxa); un problema que Occidente estaba en esos momentos en vías de solventarse al considerar al heredero del trono como "rey en potencia", cuyos derechos estaban asegurados por la ley, y por tanto su posición se hizo cada vez más firme e inatacable, ya fuera desde dentro de la familia real o desde otros poderes.

Por todo ello, el ejercicio del derecho dinástico, aunque cada vez más fuerte, no suprimía por entero lo aleatorio que conllevaba todo advenimiento al Imperio, en especial porque ahora serían las grandes familias aristocráticas bizantinas las que unidas por estrechos lazos familiares consideraran el trono como algo privativo, que no podía salir de un estrecho círculo familiar. Por ello al final de la época de la Dinastía Macedonia la división política en los círculos cercanos al poder quedaba plasmada en la pertenencia al denominado partido civil (funcionarios y senadores) y al conocido como partido militar (estrategas y generales).

Por ello el resto del siglo XI fue una lucha constante entre estos partidos y las grandes familias que había detrás de ellos por asegurarse el trono, recordemos que la anciana emperatriz Teodora había aceptado elegir como sucesor a un veterano miembro de la nobleza palatina (partido civil), Miguel VI Estratiótico, que tras ser legalmente adoptado por Teodora recibió oficialmente la Corona ${ }^{3}$. El anciano Miguel VI (1056-1057) favoreció claramente al partido civil de los bu-

J.M a de Francisco Olmos, "Los inicios de la moneda dinástica en Bizancio. La Casa de Justino y los Heráclidas", Documenta \& Instrumenta, $\mathrm{n}^{\circ} 7$ (2009), pp.123-148, donde se trata este problema y su relación con las acuñaciones de los emperadores en los siglos VI y VII.

2 J.M a de Francisco Olmos, "El Triunfo de la moneda dinástica en el Imperio Bizancio. Isaurios. Amorianos y Macedonios", Documenta \& Instrumenta, no 8 (2010), pp. 87-114, donde se trata este problema y su relación con las acuñaciones de los emperadores en los siglos VIII-XI.

3 Su verdadero nombre era Miguel Bringas, recibiendo el sobrenombre de "Stratiocius" por el cargo burocrático que desempeñaba.dentro de la administración. 
rócratas de la corte en detrimento de la poderosa aristocracia militar, y por ello terminó siendo depuesto por el partido militar dirigido por el estratega Isaac I Comneno (1057-1059), líder de la aristocracia militar de Asia Menor, que fue proclamado emperador por sus tropas en junio de 1057 y ocupó el trono sin grandes problemas ${ }^{4}$.

Las monedas de Isaac I llaman la atención por un hecho importante que fue muy comentado en la época, ya que decidió mostrarse en una de ellas con la espada desenvainada sobre el hombro, lo que se consideró una arrogancia, ya que parecía indicar que había llegado al trono únicamente por el poder del ejército, y esto era impensable en Bizancio, donde se consideraba que la Providencia Divina era quien designaba al emperador. Este fue el motivo de que casi de forma inmediata acuñara otra pieza con características más acordes a la tradición bizantina, apareciendo ahora el emperador con la espada envainada a un costado y sosteniendo el labarum (estandarte imperial) con la mano derecha, una tipología que ya había sido usada por el emperador Constantino IX apenas unos años antes 5 .
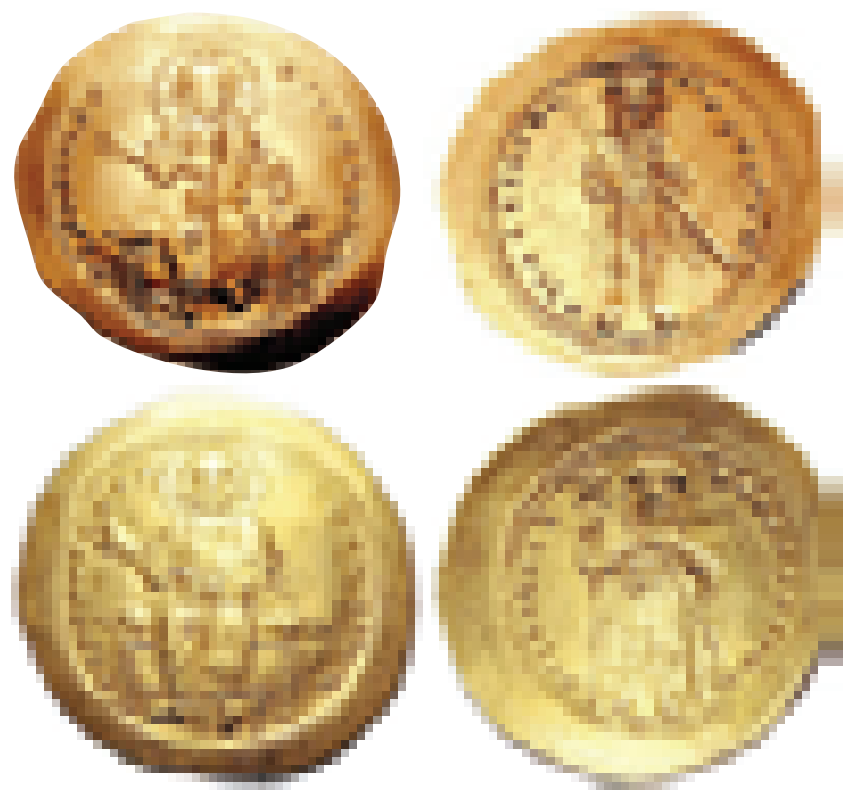

Isaac gobernaría poco más de dos años, su hijo Manuel había muerto con anterioridad, y su hermano Juan no aceptó el trono, por lo cual el emperador decidió abdicar ( 22 de noviembre de 1059), aconsejado por Miguel Psellos, en uno de los miembros de una de las más poderosas familias de la aristocracia civil, Constantino Ducas, que fue coronado el día siguiente, mientras Isaac se retiraba al monasterio de Studion, donde murió un año después.

4 A esta proclamación siguieron negociaciones entre las partes, Miguel Psellos en nombre de Miguel VI propuso a Isaac ser nombrado César y sucesor del trono, lo que éste aceptó, pero la situación en la capital era tan inestable que Miguel VI se vio obligado a abdicar (30 de agosto), Isaac entró en la ciudad al día siguiente y fue solemnemente coronado como emperador el 1 de septiembre, fecha de inicio oficial de su reinado, por el Patriarca Miguel Cerulario. Tras su deposición Miguel VI no fue condenado a muerte, ni cegado, ni exiliado, como solía ser habitual, sino que se le permitió retirarse a la vida privada, a un monasterio, donde murió poco después

5 Para las referencias de las monedas ver A. Bellinguer, Ph. Grierson y M.F. Hendy, Catalogue of the Byzantine Coins in the Dumbarton Oaks Collection and in the Whittemore Collection (DOC), Washington, 1992-1999. DOC III/2 Isaac $\mathrm{n}^{\circ} 2$ (espada al hombro), $\mathrm{n}^{\mathrm{o}} 1$ (tipo espada envainada). 
Constantino X Ducas (1059-1067), estaba muy bien relacionado, de hecho su mujer, Eudoxia Makrembolitissa, era sobrina del poderoso e influyente Patriarca de Constantinopla, Miguel Cerulario, el artífice de la ruptura política y religiosa con Roma en 1054. Constantino X, siguiendo los modelos anteriores, fortaleció a su familia: su hermano Juan fue nombrado César, su mujer Eudoxia Augusta, y sus hijos mayores, Miguel y Constantino, fueron asociados al trono, aunque no sabemos en qué fecha y llama la atención que no aparezcan en sus monedas, dónde sólo se coloca la imagen del emperador y en algunas escasas ocasiones la de la emperatriz. A su muerte la Regencia quedó oficialmente en manos de su viuda (1067), aunque el poder efectivo lo tenían el César Juan Ducas y Miguel Psellos (brillante intelectual y político), que no pudieron impedir que el partido militar exigiera el poder, dada la desastrosa situación de las fronteras, por lo cual su líder, el general Romano IV Diógenes, se casó con la emperatriz viuda y se convirtió en emperador (1068-1071).

Ya hemos visto que éste era un modo tradicional de llegar al poder, que aseguraba la legalidad y la continuidad dinástica. Durante los seis meses de la Regencia de Eudoxia se habían acuñado monedas con la Emperatriz y sus hijos, los soberanos oficiales, en una de ellas aparece en el centro, entre Miguel y Constantino ${ }^{6}$, y en otra sólo con Miguel VII, ambos de medio cuerpo.
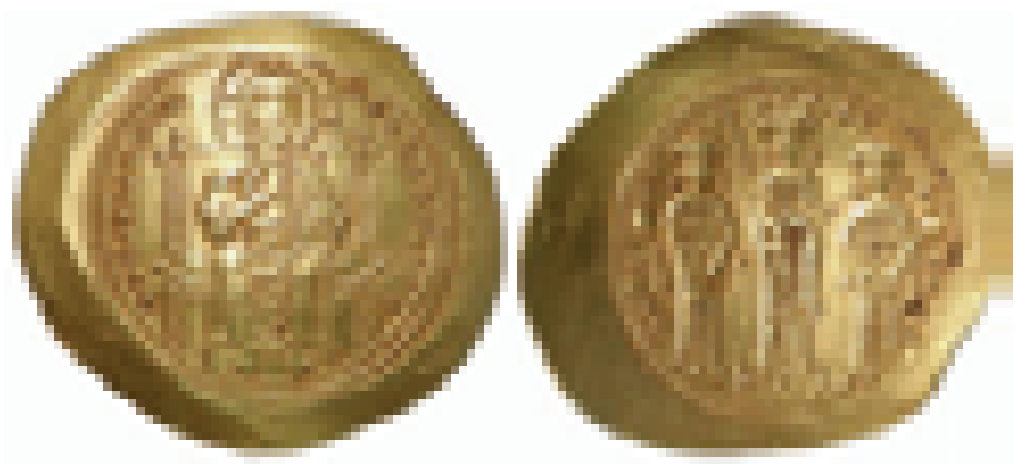

Cuando Romano IV accedió al trono una de sus primeras decisiones fue mostrar que compartía el poder efectivo con Eudoxia, acuñando una moneda donde aparecían ambos en el reverso ${ }^{7}$. De igual modo decidió asociar al trono a Andrónico, el último de los hijos de Constantino X, emitiendo entonces unas interesantes monedas donde aparece en una cara Cristo coronando a la pareja imperial, una especie de respaldo divino a la nueva situación; mientras en la otra se muestra el mantenimiento de la legalidad y la continuidad dinástica, con las figuras de los tres coemperadores hijos de Constantino $\mathrm{X}^{8}$.
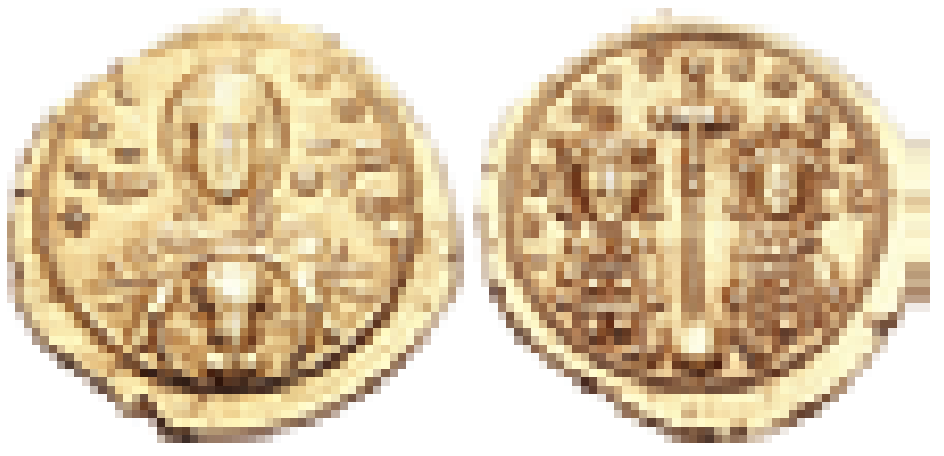

6 DOC III/2 Eudocia $\mathrm{n}^{\mathrm{o}} 1$.

DOC III/2 Romano IV n 3.

8 DOC III/2 Romano IV n ${ }^{\mathrm{o}} 1$. 

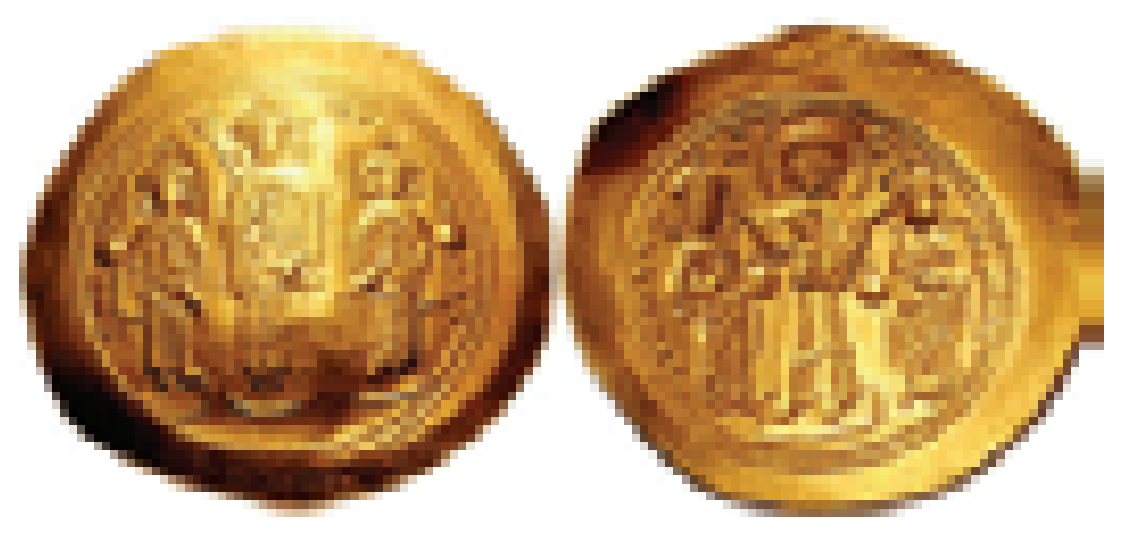

Por eso cuando Romano IV cayó prisionero de los turcos en Manzikert (agosto 1071)9 y el partido civil le declaró oficialmente depuesto, no hubo reticencias para aprobar un gobierno conjunto de la emperatriz Eudoxia y su hijo Miguel VII, pero casi inmediatamente Eudoxia fue recluida en un monasterio (octubre 1071) y el emperador Miguel VII Ducas (1071-1078) pasó a gobernar directamente sin ningún tipo de oposición. Casado con la inteligente María de Alania (Georgia), tuvo un hijo, Constantino, que por supuesto asoció al trono, pero en sus monedas nunca aparecieron los coemperadores, ni sus hermanos ni su hijo, sino sólo en algunas ocasiones su mujer.

Cuando los militares se rebelaron, Miguel decidió abdicar, sin encontrar a nadie de su familia y aliados que aceptara el trono, y se retiró como monje a Studion (marzo de 1078). Mientras tanto el jefe de los rebeldes, Nicéforo III Botaniates, que decía descender de los Focas y encabezaba a la aristocracia militar de Asia Menor, entraba en Constantinopla como vencedor, y para asegurar una cierta legitimidad a su poder el anciano general se casó con la emperatriz María, lo cual no le sirvió de nada, ya que otros generales no aceptaron su "usurpación" y se rebelaron contra él, como Nicéforo Bryennios, Nicéforo Basilakios y Nicéforo Melissenus. El vencedor final en esta contienda fue Alejo Comneno, sobrino del emperador Isaac I, casado con Irene, la nieta del César Juan Ducas, y apoyado por la emperatriz María, que le consideraba el protector de los derechos de su hijo Constantino. Sus relaciones eran óptimas y una especie de consejo familiar DucasComneno decidió utilizar todas sus influencias para llevarle al trono, y por ello Nicéforo III aceptó abdicar y Alejo se convirtió en emperador (abril de 1081).

Alejo I transformó muchas instituciones del estado bizantino y fortaleció a la Familia Imperial, pero aún así no pudo regular la sucesión Tras subir al trono cumplió su promesa de reconocer como heredero a Constantino Ducas (el hijo de Miguel VII), a quien prometió en matrimonio con su hija mayor, Ana. Pero el nacimiento de su propio hijo Juan le hizo cambiar de opinión y, en 1092, tomó la decisión de realizar una gran ceremonia donde Juan fue coronado solemnemente como coemperador ${ }^{10}$. Como muestra de la importancia que el emperador daba a este hecho, or-

\footnotetext{
9 Romano IV firmó un tratado con los selyúcidas y quedó en libertad poco después, pero cuando volvía a Constantinopla fue atacado por los nuevos gobernantes, a ellos se rindió a cambio de su seguridad personal, pero una vez en su poder fue cegado con hierros candentes, muriendo poco después a consecuencia de las heridas recibidas (verano 1072).

10 La posterior muerte del joven Ducas solucionó el posible conflicto sucesorio, aunque su hija Ana nunca se resignó a perder el trono. Tras volver a casarse con Nicéforo Bryennius, que recibió la dignidad de César, luchó porque fuera su marido el que sucediera a su padre, siendo apoyada por su madre, la emperatriz Irene, e incluso llegó a preparar un atentando contra su hermano, pero fracasó. Al final Ana Comnena terminó retirándose a un monasterio para dedicarse a los estudios, componiendo un magnífico trabajo de historia, la Alexiada.
} 
denó la acuñación de una moneda, conocida como "de la coronación", cuya misión era reflejar la nueva situación sucesoria (que coincide con la profunda reforma que el emperador hizo del sistema monetario el 1 de septiembre de 1092). En el reverso aparecen Alejo I y su mujer Irene, y en el anverso está el joven Juan II siendo coronado por el mismo Cristo ${ }^{11}$, muestra de la excepcionalidad de esta situación es el hecho de que desde entonces el coemperador Juan no apareció en ninguna otra moneda.
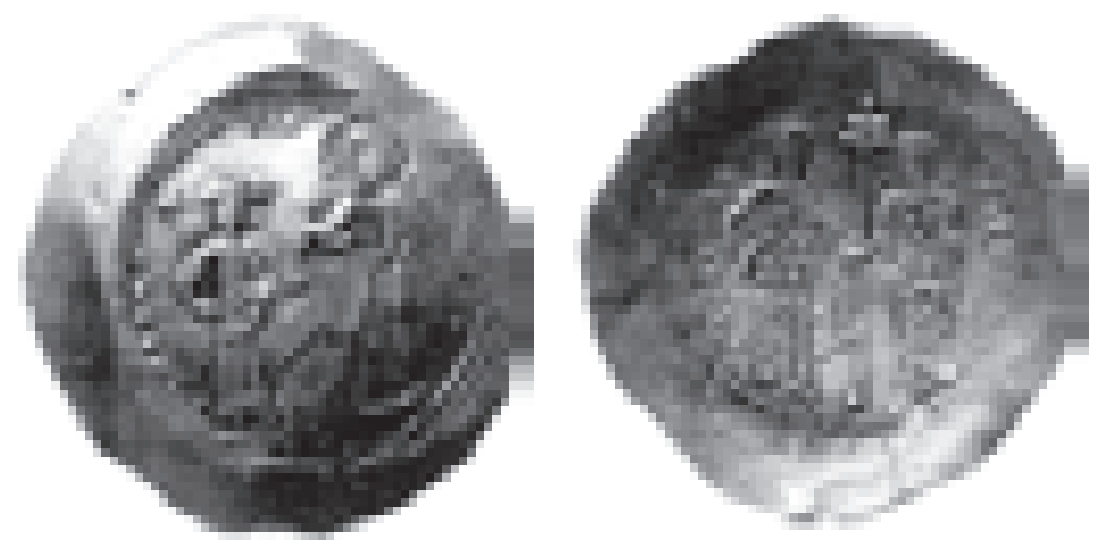

A partir de este momento y hasta la caída de Constantinopla en manos de los latinos (1204) ya no aparecerá ningún coemperador en las monedas, se potenciará cada vez más el papel del emperador como elegido de Dios, apareciendo en las estampas monetarias señalado por la "Manus Dei" " ${ }^{2}$, Cristo, la Virgen o algún santo que venerara de forma especial (en especial santos militares, como el Arcángel San Miguel, San Teodoro o San Constantino), aunque las asociaciones al trono se mantuvieron como modo de establecer la sucesión, aunque la voluntad imperial siguió primando sobre cualquier tradición o costumbre ${ }^{13}$.

11 DOC IV/1 Alejo I n ${ }^{\circ}$ 21, pieza extremadamente rara (asaron trachy nomisma de Constantinopla).

12 Sobre la utilización política de este elemento iconográfico en la moneda bizantina ver José Ma de FRANCISCO OLMOS, “La Manus Dei en la Moneda Bizantina, siglos VIII-XII”, Crónica Numismática no 176 (diciembre 2005), pp.4043, donde se ve con detalle su uso por Alejo I.

13 Juan II (1118-1143) asoció casi de forma inmediata a su primogénito Alejo (1119), que moriría en 1142, y tras este hecho decidió que debía sucederle su hijo más joven, Manuel I (1143-80), sin duda el más brillante, un ejemplo de la superioridad de la voluntad imperial sobre cualquier ley o costumbre, al eliminar de la línea sucesoria a sus otros hijos. Otro ejemplo de la no existencia de normas sucesorias y la fuerza de la voluntad del emperador es la decisión que tomó Manuel I para acabar con la interminable guerra en los Balcanes. El emperador rompió con la tradición y ordenó casar a su hija con el príncipe heredero de Hungría, Bela, que se había educado en Constantinopla, y de esta manera hacerle heredero de ambos estados con el nombre de Bela-Alejo, para lo cual se le entregó de forma inmediata el gobierno de Croacia y Dalmacia, así como el título de Déspota, hasta entonces reservado en exclusiva para el emperador, colocándole de esta manera en el segundo lugar del Imperio (por delante del Sebastocrátor y del César). Pero el nacimiento de su hijo Alejo II le hizo cambiar de opinión, asociando al trono al pequeño de dos años (1171), que subiría al trono a los 12 bajo la regencia de su madre, María de Antioquia, lo cual provocó la ira de los contrarios a la tendencia latinófila del gobierno y de muchos miembros de la familia imperial, que encontraron un líder en otro miembro de la familia, Andrónico, que tomó el poder en medio de un caos sangriento, para luego hacerse coronar coemperador "a instancias del clero y el pueblo" (septiembre 1183). Inmediatamente el joven Alejo II fue estrangulado y su cadáver arrojado al mar, mientras Andrónico I, con objeto de fortalecer su legitimidad, se casaba con su joven viuda Ana, hija del rey Luis VII de Francia. Su gobierno fue el último de la dinastía, que desapareció cuando los normandos entraron en Constantinopla y el emperador fue descuartizado en las calles por una enloquecida turba (septiembre de 1185). 
Tras la caída de los Ducas, llega la última etapa de decadencia bizantina con el gobierno fratricida de la familia de los Angel y la caída de Constantinopla en poder de los latinos ${ }^{14}$. Mientras tanto los griegos deben refugiarse en pequeños estados menores (Nicea, Trebisonda, Tesalónica, Epiro, etc.), manteniendo viva la llama de la independencia y de la fe ortodoxa, esperando el momento de recuperar su poder perdido, simbolizado en la reconquista de Constantinopla.

El más importante de los estados griegos fue el llamado Imperio de Nicea, que se consideraba heredero de la legitimidad bizantina, tanto en el plano político como en el espiritual, ya que allí se trasladó el Patriarcado griego ortodoxo de Constantinopla, que avaló al nuevo gobernante, Teodoro Comneno-Láscaris (1254-1258). La sucesión de este Imperio siguió las normas bizantinas, la voluntad del emperador era soberana. Teodoro I entregó el trono a su yerno, Juan III DucasVatatzes (1222-54), en detrimento de sus propios hermanos, que se rebelaron aliándose con los latinos y fueron totalmente derrotados. A Juan III le sucedió sin problemas su único hijo, Teodoro II (1254-58), y a éste su joven hijo Juan IV (1258-1261), de sólo siete años, que quedó bajo la regencia del plebeyo Jorge Muzalón, algo que los grandes aristócratas, dirigidos por Miguel Paleólogo, no aceptaron. En la misma misa de difuntos de Teodoro II (agosto de 1258) Muzalón y sus partidarios fueron asesinados, y Miguel se convirtió en protector del joven emperador con el rango de Megaduque, para luego pasar a recibir el título de Déspota; y unos meses después fue alzado sobre el escudo y proclamado coemperador (diciembre) por el ejército, siendo coronado como tal por el Patriarca a principios del año 1259.

\section{RELACIONES DUCAS-COMNENO-ANGEL}

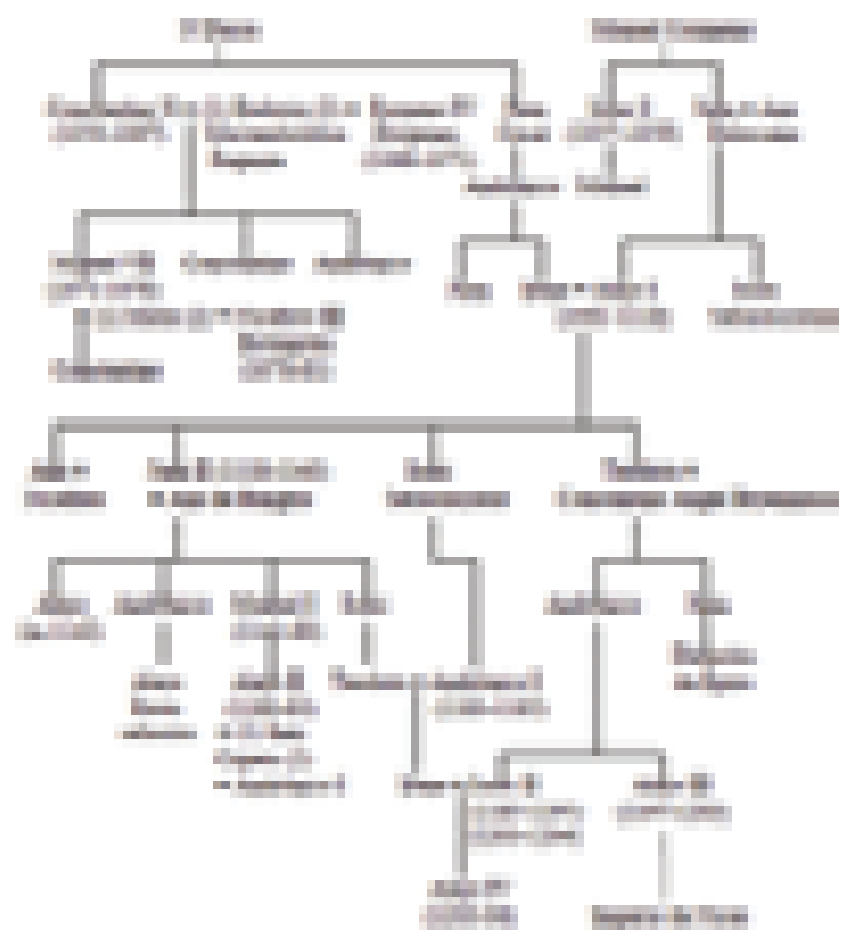

14 Isaac II (1185-1195) perdió el trono en una revuelta dirigida por su hermano mayor, Alejo III, que ordenó cegarle. El hijo de Isaac II buscó venganza en Occidente, consiguiendo la ayuda de los cruzados que se dirigían a Oriente. En 1203 tomaron Constantinopla, nombrando emperador al ciego Isaac II y su hijo Alejo IV, que al no cumplir sus promesas económicas vieron como los cruzados saqueaban la ciudad y acababan formalmente con el Imperio, se lo repartían y creaban su propio Imperio latino. 


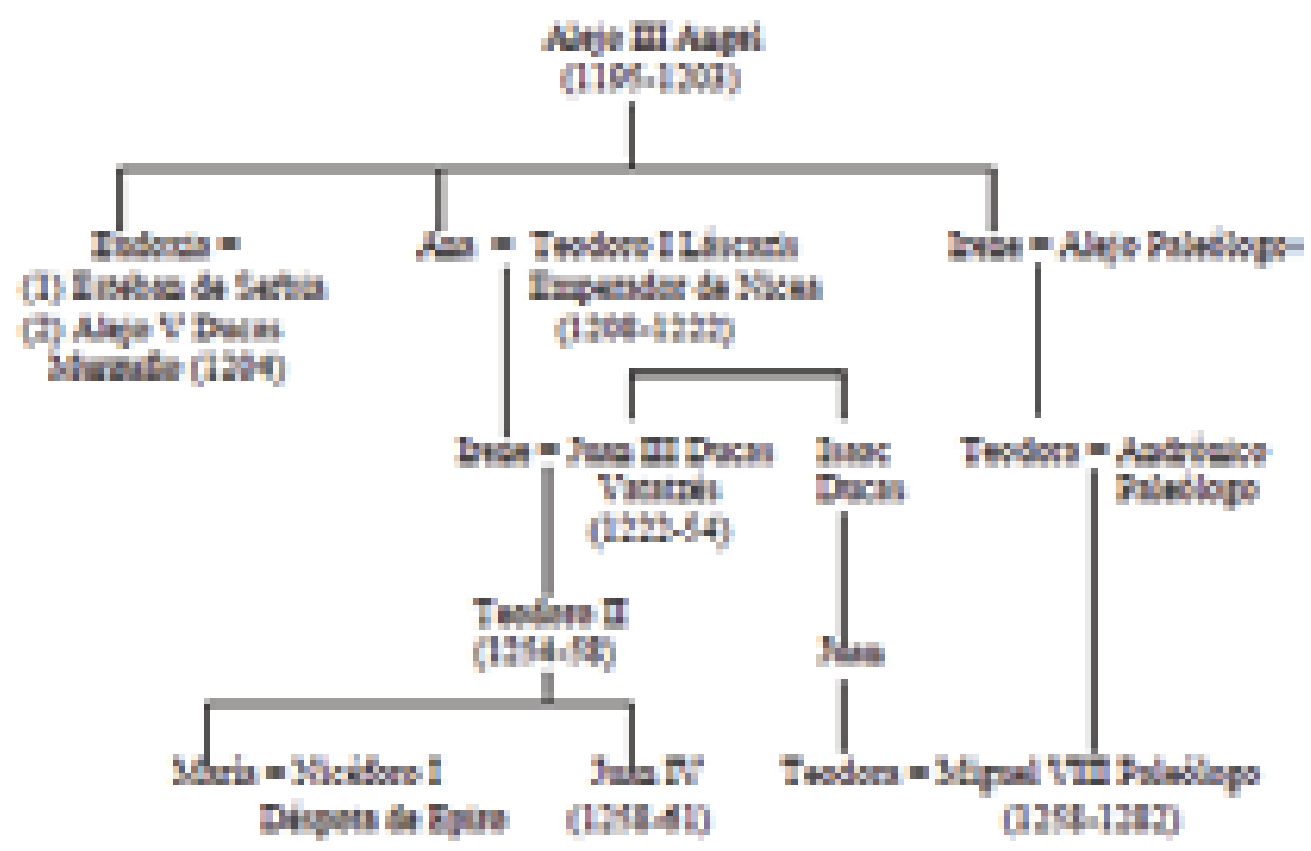

\section{LOS PALEÓLOGOS}

Miembros de una antigua familia aristocrática, su llegada al poder coincide con el declinar del Imperio Latino impuesto en 1204. Miguel VIII, como jefe del ejército del Imperio de Nicea, aprovechó la minoría de edad de Juan IV para convertirse en coemperador y gobernante de facto, algo que ya había ocurrido frecuentemente en épocas anteriores, cuando el hombre "providencial" tomaba las riendas del estado aunque manteniendo al emperador legítimo en el trono como garantía de legitimidad en el ejercicio del poder.

Miguel VIII era un gran político y consiguió culminar la reconquista bizantina aliándose con los genevoses (tratado de Ninfea, 13 de marzo de 1261) y tomando Constantinopla (25 de julio de 1261), donde hizo su entrada triunfal el 15 de agosto, y como muestra pública de la restauración imperial fue coronado solemnemente en Santa Sofía junto a su esposa (septiembre), mientras su hijo Andrónico (tres años), era proclamado como coemperador. En medio de estos festejos se echó en falta la figura del legítimo emperador, Juan IV, que permanecía en Nicea

Antes de finalizar el año Miguel VIII realizó su último movimiento para convertirse en único emperador, ordenó cegar al joven Juan IV y le encerró de por vida en la fortaleza de Dacityza. Se retrocedía así en la implantación del principio dinástico, pero el horror que produjo aquel crimen, incluso entre los servidores más cercanos de Miguel VIII, nos demuestra la fuerza que había adquirido el sentimiento de respeto a la legitimidad dinástica. Miguel pasó por la vergüenza de ser excomulgado por el patriarca Arsenio y de aguantar públicamente sus reproches. La deposición inmediata de Arsenio por orden imperial no calmó la indignación del pueblo. Miguel sólo pudo justificarse alegando la voluntad divina, y en su autobiografía se justifica con esta frase: "¿Quién, pues, Señor, proclamará tu poderío? tu diestra es la que me ha elevado" ". Como todo usurpador

15 C. Chapman, Michel Paléolegue, restaurateur de l'Empire byzantin, París, 1926, pp. 166-168. 
se creía un instrumento de la Providencia y justificaba su crimen por la razón de Estado. En sus monedas aparece de rodillas bajo la protección del Arcángel San Miguel, siendo coronado por el mismo Cristo, mientras en el reverso aparece la Virgen, en este caso la de Blanchernas, protectora de Constantinopla, rodeada de las murallas de la ciudad reconquistada ${ }^{16}$.
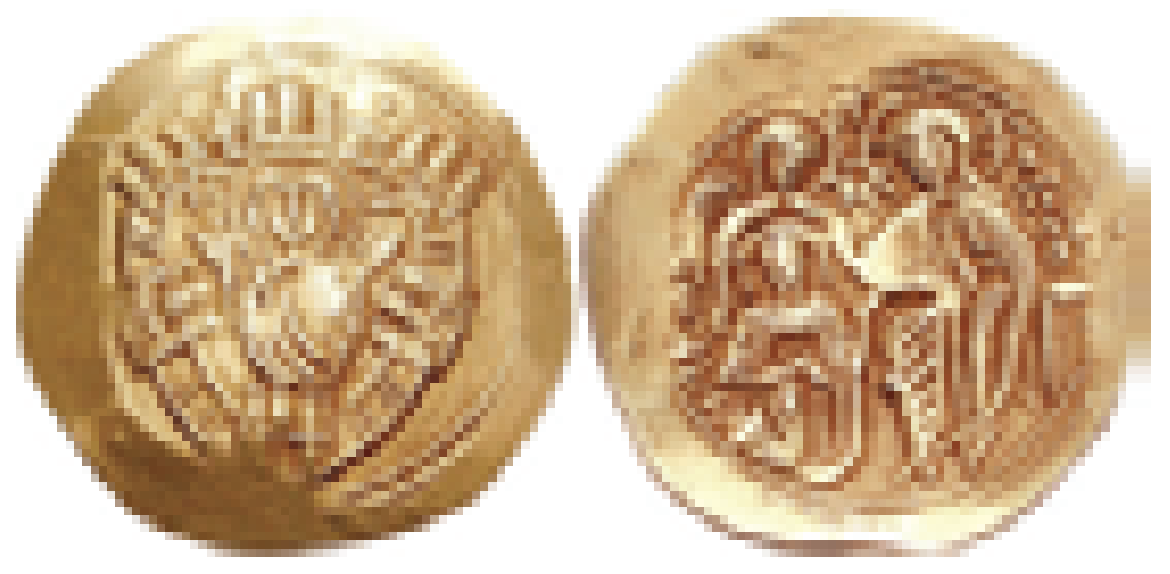

Como cuatro siglos antes los Macedonios, los Paleólogo se iban a beneficiar de la nueva legitimidad y de la aureola victoriosa de su fundador, y salieron airosos de dos prolongadas guerras civiles, una conflictiva minoría y un período de usurpación, conservando el trono hasta la caída definitiva del Imperio.

Miguel VIII era consciente de su poder y del modo en que llegó a él, y quiso asegurar el trono para su familia. Su hijo Andrónico II fue proclamado coemperador en 1261, pero no fue solemnemente coronado hasta el 8 de noviembre 1272, fecha en que el emperador publicó el prostagma, donde especificaba los derechos y atribuciones del emperador asociado, siendo uno de ellos el uso del título de autocrator, hasta entonces reservado al emperador senior, dejando claro que en caso de haber más de un emperador asociado sólo uno de ellos podía llevar este título, lo cual le convertía en una especie de heredero designado. Es en este momento cuando se acuñan las monedas con ambos emperadores (1272-1282) bajo la protección de la divinidad (Cristo) o de algún santo (Miguel, Nicolás, Jorge, Demetrio, Teodoro) ${ }^{17}$.
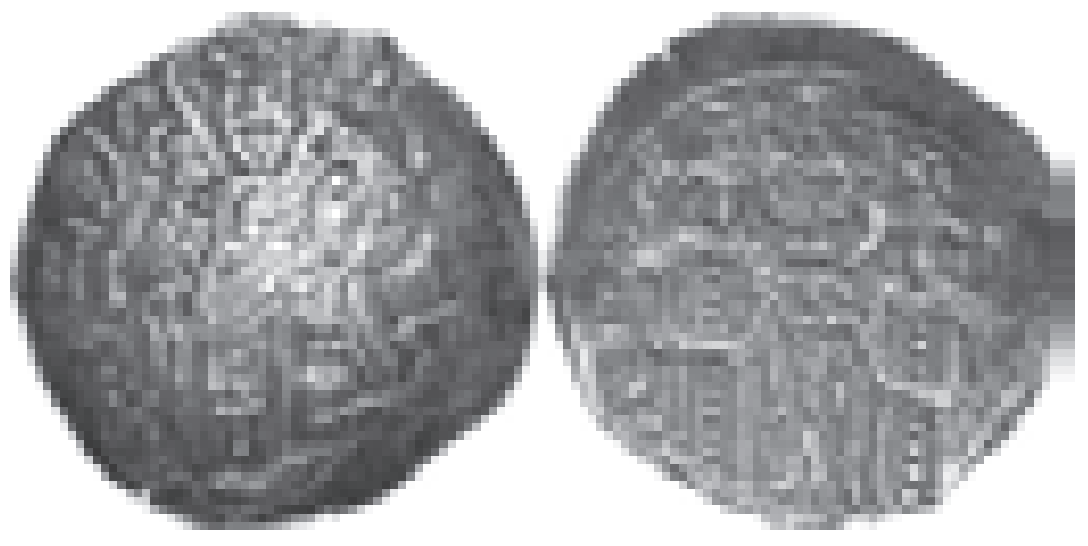

16 DOC V/2 Miguel VIII n ${ }^{\circ} 1$.

17 DOC V/2 Miguel VIII n ${ }^{\circ}$ 197. En el reverso se ve un busto de Cristo en la parte superior, que se coloca sobre las figuras de Miguel y Andrónico en actitud de protección; en el anverso aparece la figura de San Nicolás. 
Después de varios siglos volvía a la moneda la figura del emperador asociado, además ahora con muchos mayores poderes y atribuciones, reconocidos en la ley. Andrónico II (1328-1341) siguió la tradición paterna y asoció al trono a su hijo Miguel IX (21 de mayo de 1295) y como tal desempeñó un importante papel político en el gobierno del Imperio, lo que parecía llevar hacia un sistema donde toda la familia imperial iba a adquirir responsabilidades concretas de gobierno en las distintas partes del recuperado Imperio recuperado. Se iniciaba así un modelo basado en una especie de soberanía colectiva de tipo piramidal basada en la unidad familiar. Esta nueva situación de gobierno se plasma en las monedas, donde ambos emperadores aparecen juntos en distintas posiciones, las más comunes son: en el oro de rodillas ante Cristo que les está coronando ${ }^{18}$, y en la nueva moneda de plata en el reverso, de pie y sosteniendo la cruz entre ambos ${ }^{19}$.

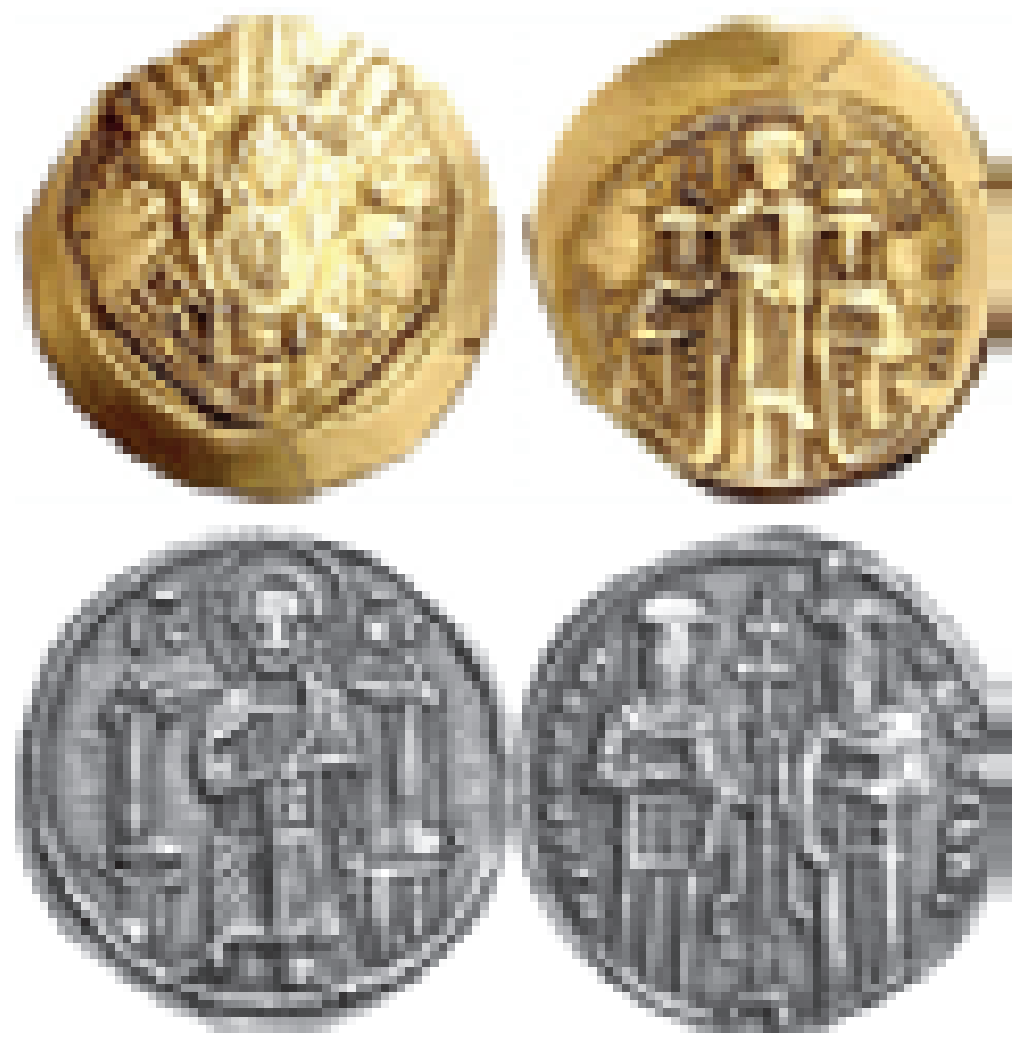

Tras la temprana muerte de Miguel IX (12 de octubre de 1320), el emperador tuvo que enfrentarse a la ambición de su nieto, el primogénito de Miguel, Andrónico III, que llegó a rebelarse y a ocupar una parte del Imperio, que gobernó de forma autónoma (1321), hasta que su abuelo aceptó finalmente nombrarle coemperador (2 de febrero de 1325), pero la lucha siguió de forma intermitente y el viejo Andrónico II fue forzado a abdicar (24 de mayo de 1328) y retirarse a un monasterio (1330).

Andrónico III (1328-1341) sólo tuvo un hijo, Juan V (1341-1391) (nacido a finales de 1331), y parece que no llegó a ser oficialmente asociado al trono, lo cual no fue obstáculo para que a la muerte de su padre fuera reconocido como emperador (junio) y coronado de forma solemne (noviembre). El problema fue el gobierno durante su minoría, en principio quedó en manos de

18 DOC V/2 Andrónico II n $\mathrm{n}^{\mathrm{O}} 235$.

19 DOC V/2 Andrónico II n ${ }^{\circ} 504$ (basilikon de plata). 
su madre, Ana de Saboya (1341-1347), época en que se acuñan unas interesantes monedas donde aparece el difunto emperador Andrónico III arrodillado ante Cristo que le bendice, mientras la Regente y su hijo aparecen compartiendo el poder en la otra cara ${ }^{20}$, esto ocurre en el oro; en la plata el diseño es similar salvo que Andrónico III bendecido por la Virgen ${ }^{21}$.
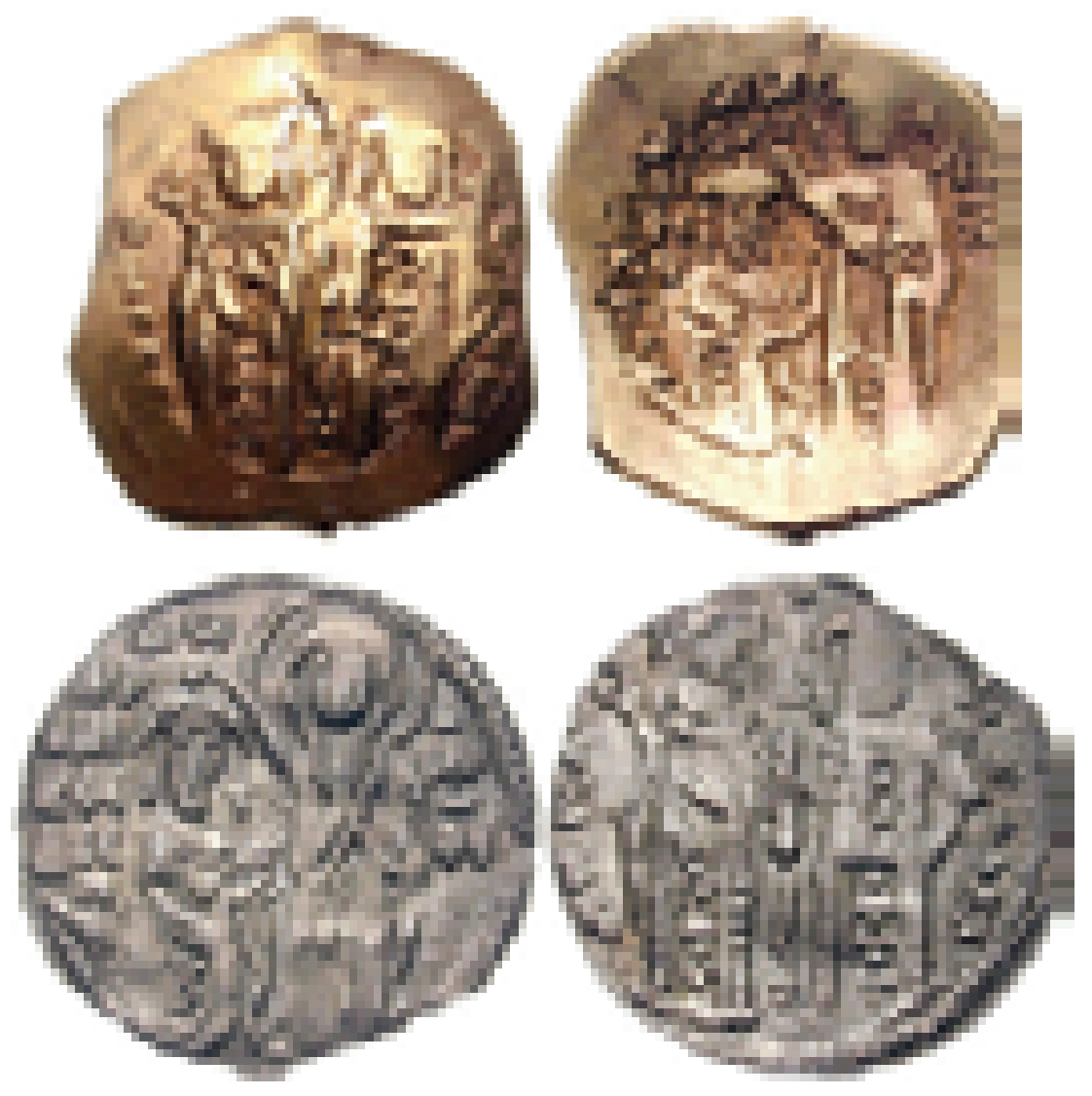

En otra variedad se muestra a Cristo coronando a Juan V, mientras el reverso está ocupado por su padre Andrónico III y San Demetrio ${ }^{22}$; y en unas piezas extremadamente raras aparece Cristo coronando a Juan V en una cara y en la otra es la Virgen quien corona a su madre Ana ${ }^{23}$, una muestra indicativa de que compartían el poder de forma efectiva, ya que en las siguientes emisiones aparecen de nuevo juntos con las tipologías tradicionales ${ }^{24}$.
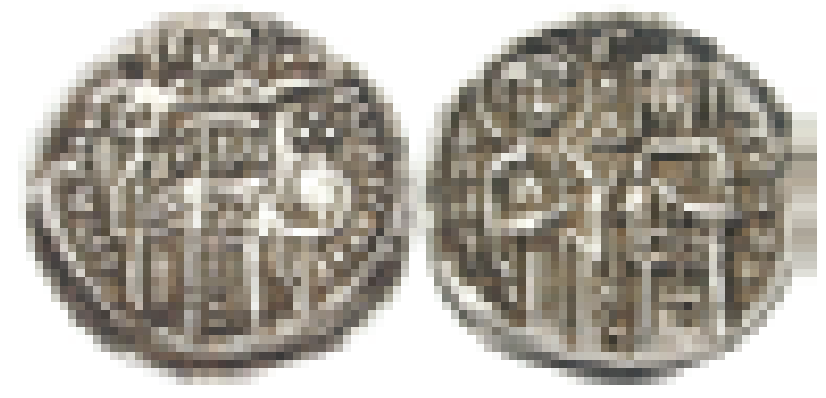

$20 \quad \mathrm{DOC}$ V/2 Juan $\mathrm{V} \mathrm{n}^{\circ} 942$.

21 DOC V/2 Juan V n ${ }^{\circ} 947$.

22 DOC V/2 Juan V n ${ }^{\circ} 944$.

23 DOC V/2 p.178.II (ver D.R. SEAR, Byzantine coins and their values, London, 2000, $\mathrm{n}^{\circ} 2509$ ).

24 DOC V/2 Juan V n 1145. 

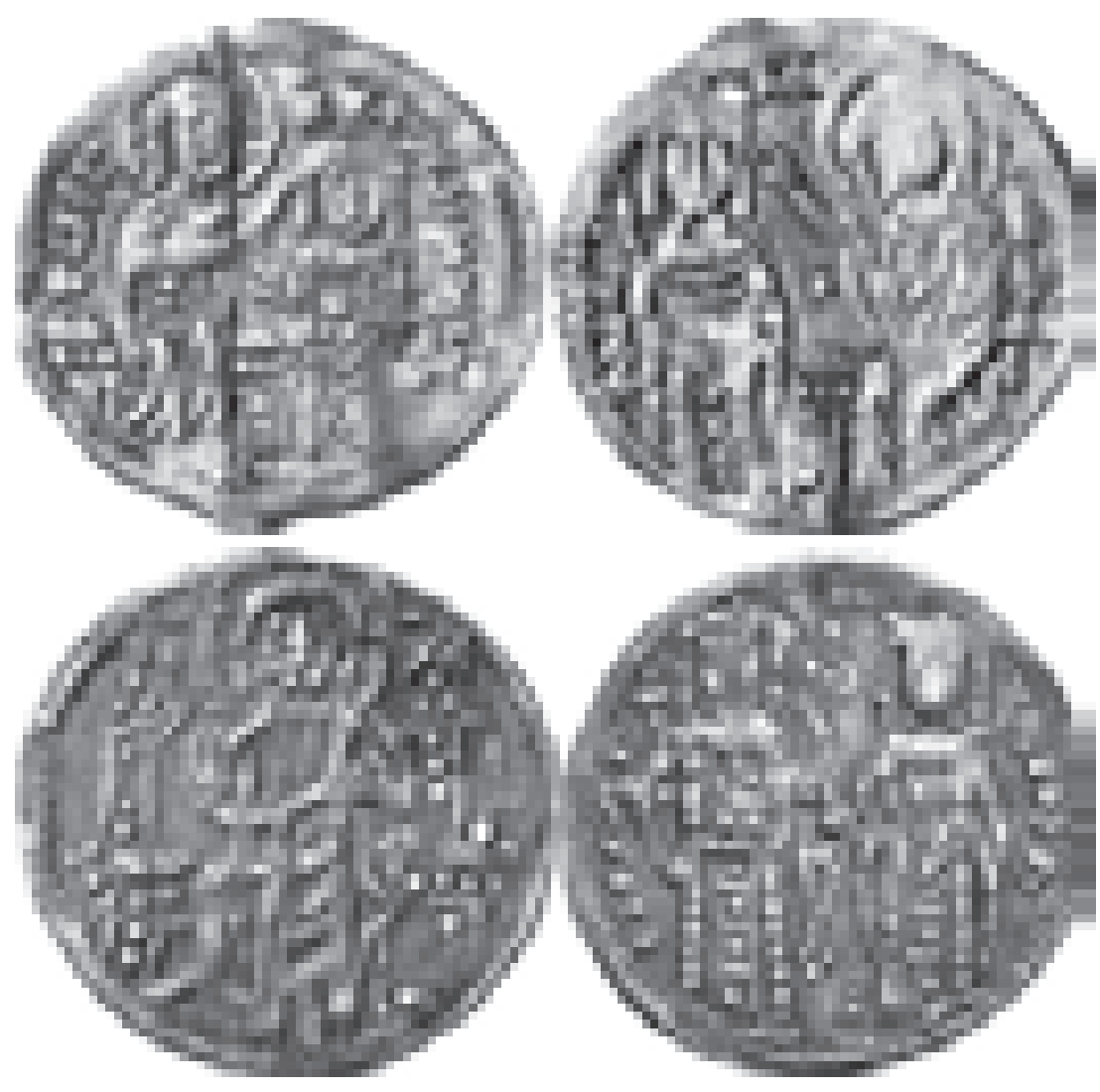

Todas estas emisiones muestran la debilidad del gobierno, socavado desde dentro por las ambiciones del Gran Doméstico Juan Cantacuzeno y por los ataques del exterior, tanto es así que estalló la guerra civil cuando Cantacuzeno se declaró emperador (octubre de 1341), aunque aceptando, como se hacía habitualmente, la primacía del emperador legítimo, Juan V. De nuevo un ejemplo de la importancia del principio de legitimidad. Juan VI Cantacuzeno venció y entró en Constantinopla en febrero de 1347, casando a Juan V con su hija Elena, y gobernando en teoría conjuntamente (1347-1353), acuñando monedas similares a las de Miguel VIII y Andrónico II, es decir apareciendo ambos siendo coronados por Cristo ${ }^{25}$, o bien compartiendo el reverso portando las insignias imperiales ${ }^{26}$.
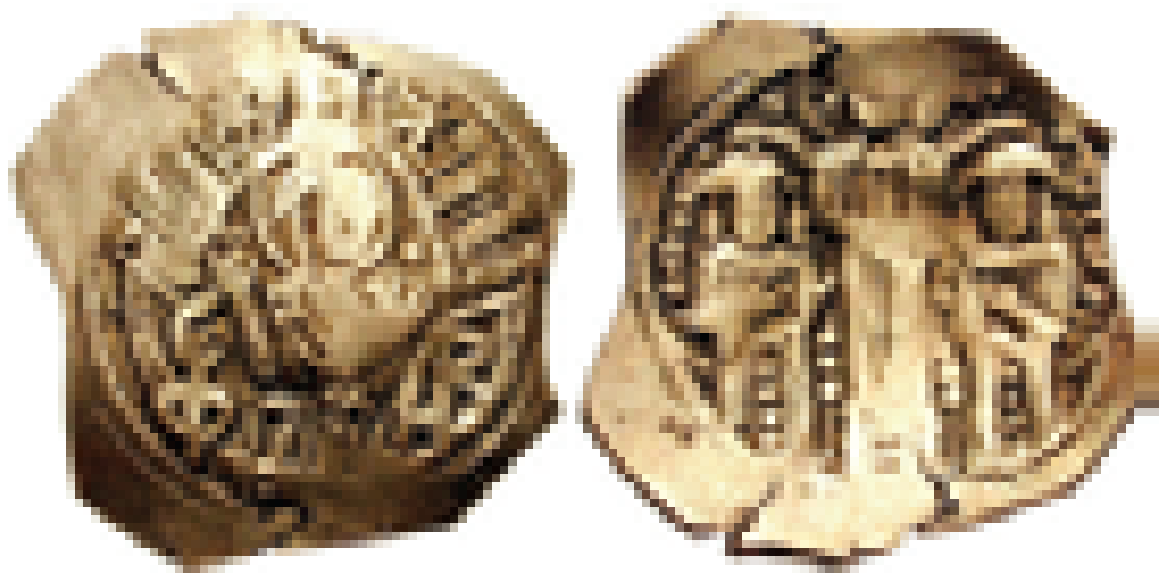

25 DOC V/2 Juan V n ${ }^{\circ} 1193$.

26 DOC V/2 p.182.2 (ver SEAR n 2528 ), Juan VI lleva el labarum y Juan V la akakia. 

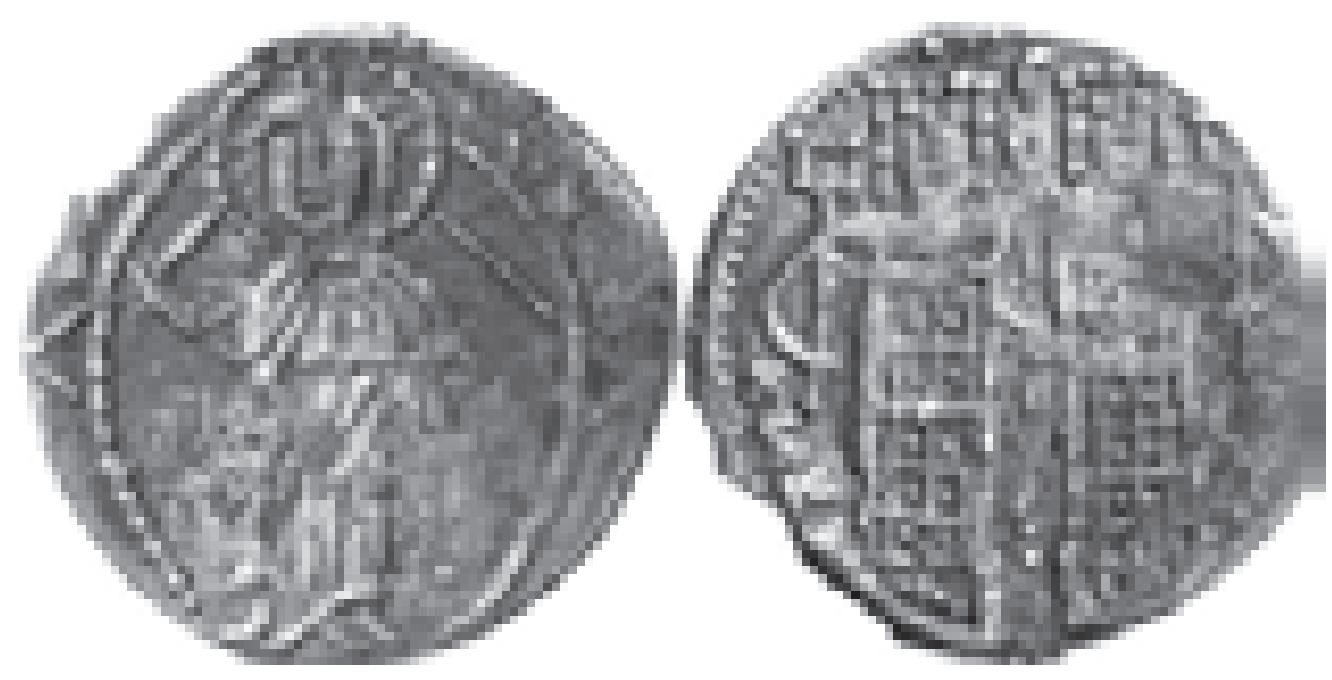

Pero la guerra civil larvada volvió a estallar y Juan V fue oficialmente depuesto, mientras Cantacuzeno nombraba coemperador a su hijo mayor Mateo (1353), deponía al patriarca (partidario de Juan V), y hacía coronar solemnemente a su hijo (1354), mientras Juan V era hecho prisionero y deportado a la isla de Tenedos. La población se opuso al cambio dinástico, Juan $\mathrm{V}$ fue libertado y entró en Constantinopla apoyado por todo el pueblo, inmediatamente Cantacuzeno fue obligado a abdicar (noviembre 1354) y a entrar en un monasterio, donde moriría treinta años después (1383), mientras su hijo Mateo continuará la lucha hasta 1357, cuando tras ser derrotado se verá forzado a renunciar a todos sus derechos a favor de Juan V.

Desde entonces hasta el final del Imperio los posibles problemas por el trono y el gobierno se produjeron únicamente dentro de la familia de los Paleólogos, pero ya no habrá monedas que nos muestren la sucesión o datos dinásticos específicos ${ }^{27}$.

27 Juan V tuvo un largo reinado lleno de complicaciones familiares, ya que además de todas las vistas anteriormente su hijo Andrónico se rebeló en varias ocasiones, y en una de ellas (1373), incluso se alió al hijo del sultán otomano para acabar con sus respectivos progenitores. No lo consiguieron y su padre (a sugerencia del sultán) ordenó cegarle y encerrarle. En ese momento Juan V nombró emperador asociado a su segundo hijo, Manuel II, que le había permanecido fiel (25 de septiembre de 1373). A pesar de todo Andrónico, que sólo había perdido la vista parcialmente, pudo escapar de Gálata, y él y su hijo Juan (VII) se convirtieron en un importante factor desestabilizador para el Imperio, tanto es así que en 1376 Andrónico (apoyado por los genoveses) consiguió ocupar la capital y encerrar a su padre y a su hermano (que a su vez consiguieron escapar con la ayuda de los venecianos). Andrónico IV gobernó hasta 1379, cuando fue expulsado por Juan $\mathrm{V}$ (apoyado por los turcos), aunque éste tuvo que aceptar (por orden del sultán) reconocerle como heredero y entregarle el gobierno de Selimvria, Heraclea, Redesto y Panidos. Andrónico IV murió en 1385, dejando a su hijo Juan como representante de su línea dinástica, que apoyado por los turcos ocupó Constantinopla como Juan VII (abril 1390), donde tenía gran numero de partidarios por considerar legítimas sus pretensiones al trono, pero fue expulsado por Manuel II unos meses después (septiembre). Juan V murió el 16 de febrero de 1391, y le sucedió Manuel II (1391-1425). Ahora el poder estaba en manos de los turcos, que no hacían sino ir poco a poco apretando el lazo a los griegos, la mayoría de los cuales ya les servían en calidad de vasallos. Manuel decidió hacer un desesperado intento y emprendió un viaje a Occidente, durante el cual entregó el gobierno del Imperio a su sobrino Juan VII de Selimvria (1399-1403), sin duda un paso arriesgado. Manuel pidió ayuda a las potencias cristianas (Francia, Inglaterra, estados italianos...), fue recibido con grandes honores, pero no consiguió nada. Manuel II volvió a Constantinopla con ánimos renovados tras la derrota turca en Ankara ante Tamerlán (1402) y siguió gobernando (mientras Juan VII rigió Tesalia hasta 1408), nombrando coemperador a su primogénito Juan VIII (19 de enero de 1421). Desde entonces se fue alejando gradualmente del ejercicio del poder para morir el 21 de julio de 1425. Le sucedió sin problemas Juan VIII (1423-1448), que no pudo sino volver a pedir ayuda a Occidente adonde marchó de 


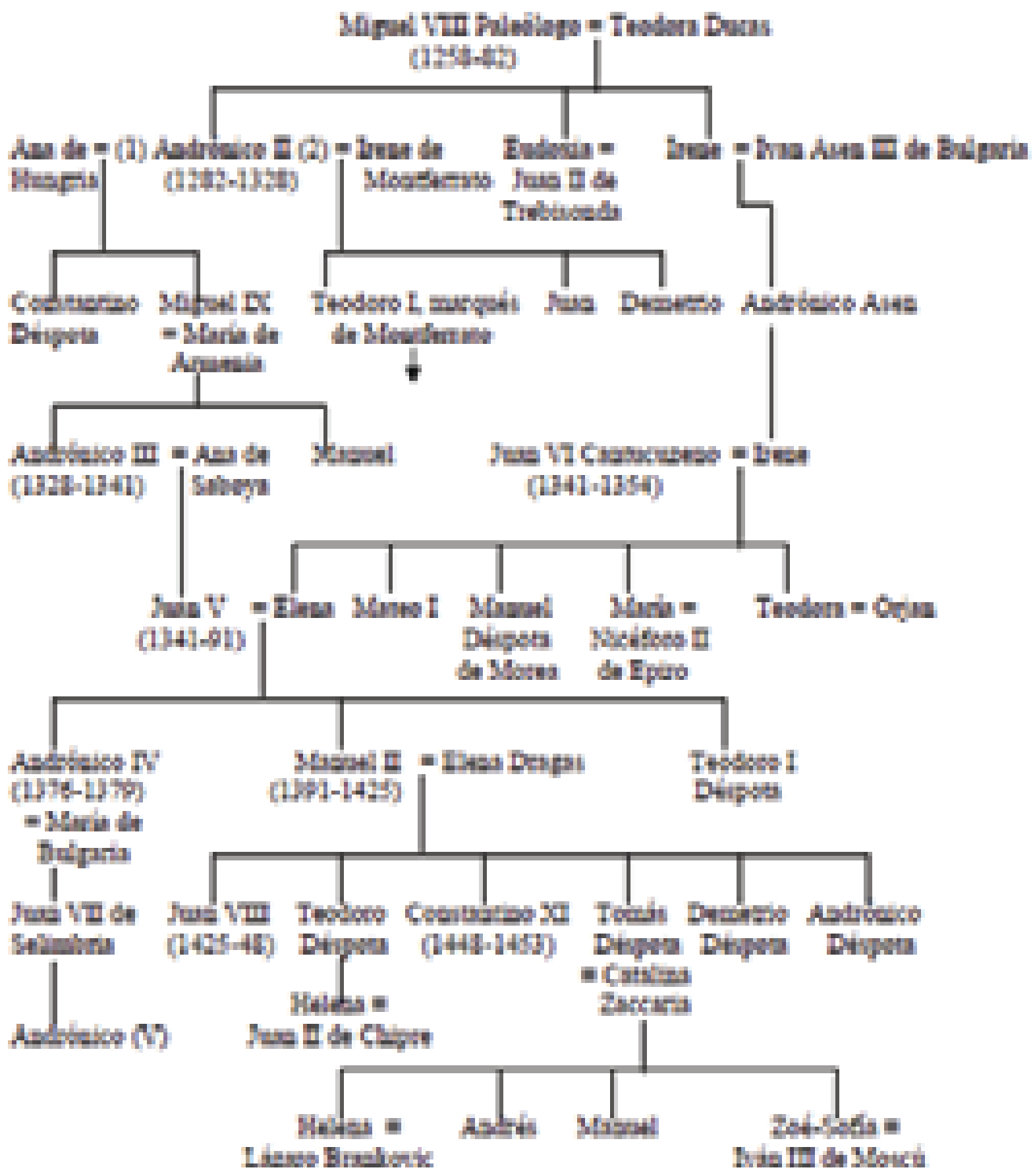

nuevo, e incluso aceptó poner fin al cisma religioso mediante un Concilio, lo cual le privó del apoyo de la población griega hostil a todo lo latino. Además Occidente no proporcionó la prometida ayuda material que tanto necesitaban los bizantinos. Juan murió sin hijos y le sucedió su hermano Constantino XI (1448-1453), que se había distinguido en el Peloponeso por su valentía, y moriría luchando contra los turcos durante el asalto final a Constantinopla el 29 de mayo de 1453. 
A la muerte del último emperador, Constantino XI (1453), la herencia imperial bizantina se desvaneció, aunque algunos de los miembros de la familia de los Paleólogos sobrevivieron. Su hermano menor, Tomás, murió en Roma en 1465, y su hija Zoé-Sofía (1448-1503), se casó en 1472 con Iván III Vassilievich, Gran Duque de Moscú (1462-1505) y gobernante de la mayor parte de Rusia, que decidió convertir su estado en el heredero oficial de Bizancio. De esta manera Moscú pasó a ser considerado la "la tercera Roma", el gobernante ruso asumió el papel de protector oficial de todas las iglesias ortodoxas del mundo, adoptando desde entonces numerosas costumbres, usos y hábitos de origen bizantino, como fueron el uso del emblema del águila bicéfala y un nuevo título para su soberano, el de Zar, forma eslava derivada de la palabra César que tradicionalmente había sido utilizada por estos pueblos para designar al emperador de Constantinopla ${ }^{28}$.

El último siglo de la Numismática bizantina muestra bien a las claras la decadencia del Imperio, la moneda de oro dejará oficialmente de acuñarse, ya no hay nuevos tipos "políticos" que nos informen de los cambios producidos en el Imperio, la calidad de las piezas es cada vez menor, y cada vez circula mayor moneda extranjera, muestra de la decadencia económica del Imperio frente a las potencias occidentales, de este modo la crisis económica se unió a la política y militar.

Este repaso a la moneda bizantina nos ha mostrado cómo durante mil años los emperadores utilizaron este extraordinario documento como su principal medio de propaganda política. Por una parte como afirmación de su omnímodo poder personal y su relación con la divinidad, y por otro como medio de promocionar la sucesión dinástica en una sociedad que la fue aceptando con reticencias, aunque desde el siglo IX demostró una importante lealtad a la Familia Imperial y no aceptaba de buen grado las usurpaciones. Por todo ello la moneda bizantina es un claro ejemplo de moneda genealógica vinculada al problema de la sucesión al trono, única en todo su ámbito cultural y muestra de la especificidad de sus instituciones.

\section{APÉNDICE LOS PALEÓLOGO DE MONTFERRATO}

Los descendientes de Aleramo di Savona, Marqués de Liguria y Piamonte, señor de Montferrato (m.986), títulos confirmados por el emperador Otón I (967), habían gobernado este pequeño y estratégico estado italiano desde finales del siglo X. Pero desde el siglo XII la familia tuvo un importante papel en el Mediterráneo oriental, estuvieron presentes en las Cruzadas y entroncaron con la familia real de Jerusalén, llegando incluso al trono, fueron también reyes de Tesalónica, y se unieron por matrimonio a los emperadores latinos de Jerusalén, a los reyes de Chipre e incluso al emperador de Bizancio, sin olvidar nunca sus tierras de Italia y sus aspiraciones expansionistas en la zona (Ivrea, Asti, Milán).

28 A este respecto hay que recordar que desde finales del siglo XV los gobernantes de Rusia nunca olvidaron esta herencia, y en su política exterior siempre estuvo presente "recuperar" Constantinopla. Recordemos el caso de Catalina II, que a finales del siglo XVIII tenía avanzados planes para restaurar el Imperio Bizantino en la persona del segundo de sus nietos, Constantino, llamado así precisamente con el objetivo de que algún día pudiera gobernar en la antigua ciudad imperial. Del mismo modo hay que decir que durante la Primera Guerra Mundial, y a raíz de la decisión de lanzar una ofensiva en los Dardanelos (desembarco anglofrancés de Gallípoli de abril de 1915), los Aliados decidieron reunirse para perfilar el futuro reparto del Imperio otomano. En marzo de 1915 Francia y Gran Bretaña accedieron a las demandas rusas, y acordaron que tras la victoria recibiría el Imperio de los zares recibiría Constantinopla, los Estrechos y una extensa zona al este de Anatolia, todo lo cual no se llevó a cabo por el estallido de la Revolución (1917) y la posterior caída y muerte de los Romanov, que llevó a las nuevas autoridades soviéticas a firmar una paz separada con las potencias centrales (Brest-Litovsk). 


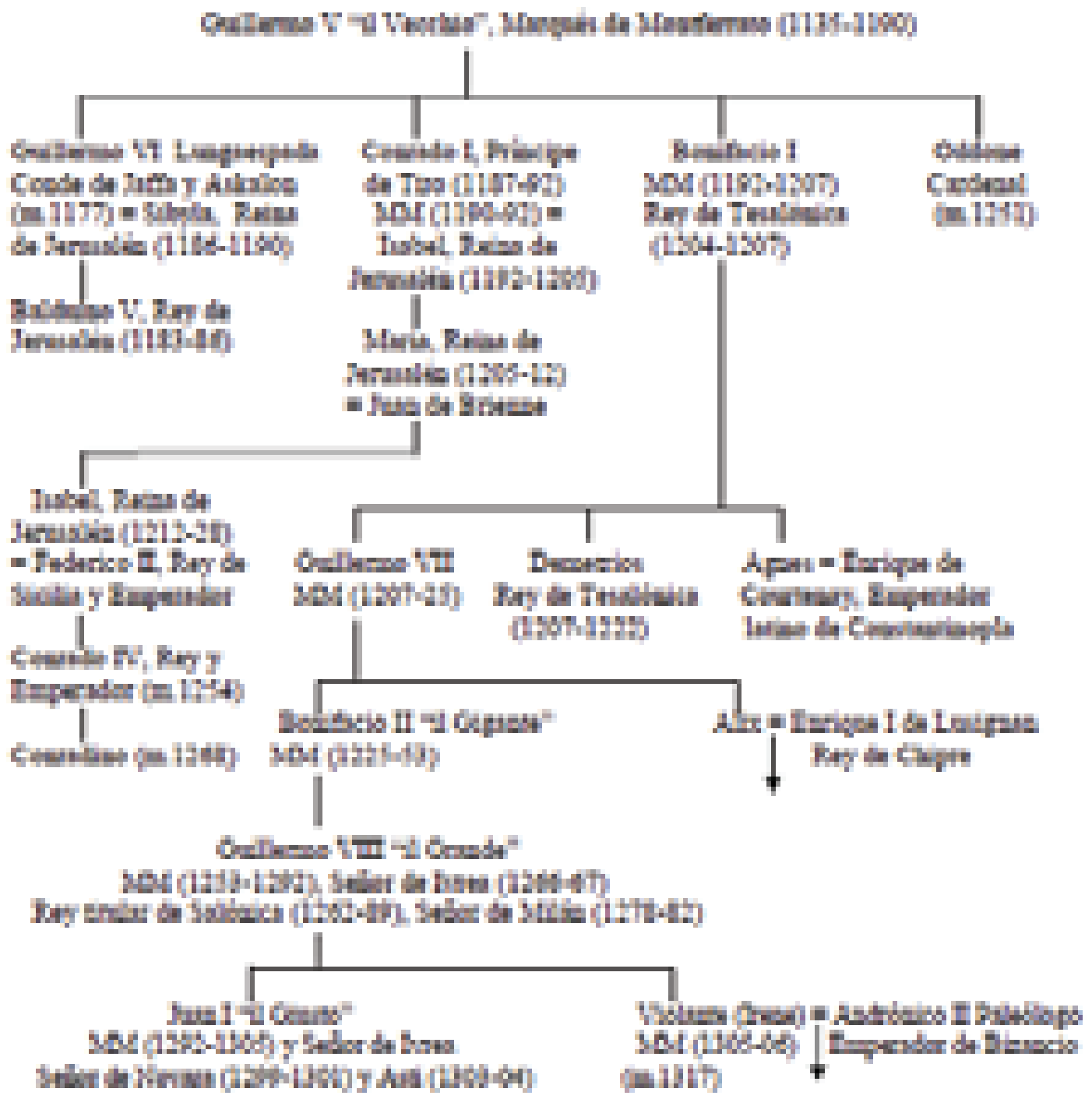

En 1305 murió el último Marqués de Montferrato de la familia de los Aleramici, y entonces este estado italiano pasó a Teodoro Paleólogo, hijo primogénito de Irene (hija de Guillermo VIII de Montferrato) y del emperador Andrónico II Paleólogo. Con Teodoro los Paleólogo pasaron a gobernar este marquesado, feudo del Sacro Imperio ${ }^{29}$, durante más de 200 años. En cuanto a las monedas acuñadas por los Paleólogo en Montferrato hay que hacer un par de comentarios, en primer lugar domina la heráldica en su tipología, y en segundo, dado que en Bizancio este arte no estaba extendido los Paleólogo tuvieron que buscar unas armas propias que denotaron su origen imperial bizantino y al mismo tiempo tuvieran cabida en la heráldica occidental. Así junto a las armas propias de Montferrato (escudo de plata con jefe de gules), pronto usarían símbolos bizantinos e imperiales, por una parte el escudo de gules con cruz de oro cantonada por las cuatro B (la primera y tercera contornadas), que representan el lema B $\alpha \sigma \imath \lambda \varepsilon v ́ \varsigma$ B $\alpha \sigma \imath \lambda \varepsilon ́ \omega v, \mathrm{~B} \alpha \sigma \imath \lambda \varepsilon v ́ \omega v \mathrm{~B} \alpha \sigma \imath \lambda \varepsilon o ́ v \tau \omega v$ (Rey de Reyes, Gobernante de los Gobernantes), y la tradicional águila bicéfala del Imperio.

29 De hecho desde 1464 tenían el título de Vicarios Imperiales. Para la sucesión ver el árbol genealógico de esta familia que aparece en las páginas siguientes. 

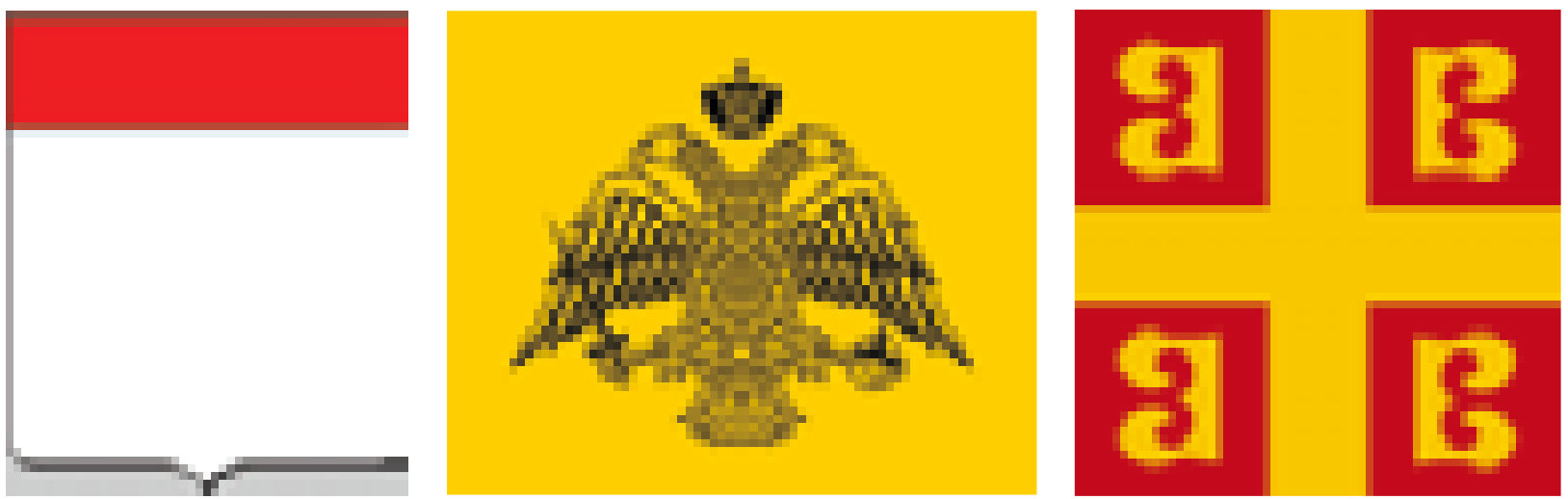

Veamos ahora algunos ejemplos concretos de monedas del Montferrato de los Paleólogos, en primer lugar una pieza de plata (testón) de Guillermo IX (1494-1518), que muestra ya algunas características renacentistas, y en la heráldica, además de los emblemas bizantinos (en los cuarteles $1^{\circ}$ y $4^{\circ}$ ) y el escusón de Monteferrato sobre el todo, coloca las armas de la ascendencia materna de su mujer, Anne de Alençon, es decir las de los Lorena (Jerusalén, Aragón, Bar...) ${ }^{30}$.
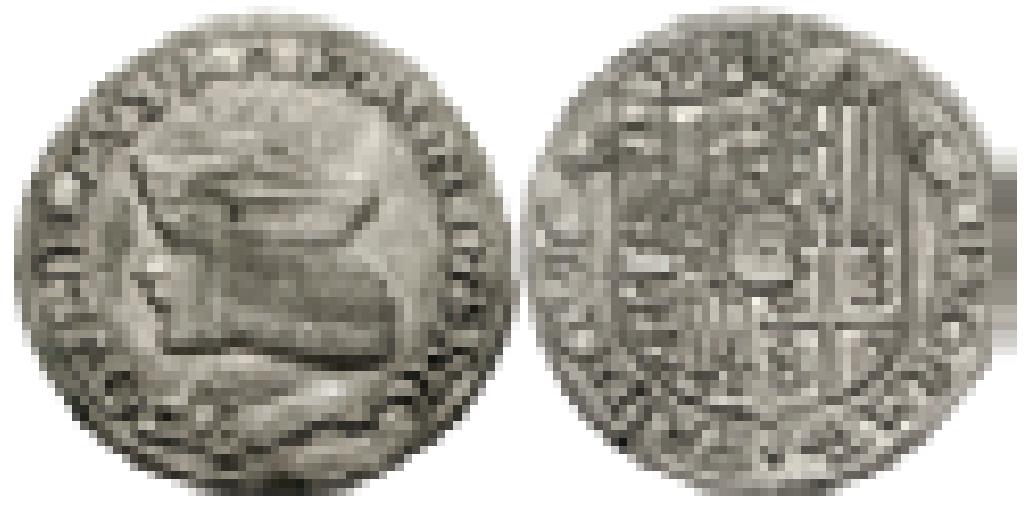

El hijo de ambos, Bonifacio IV (1518-1530), acuñó unas piezas más simples que sólo muestran las armas de la familia Paleólogo y de Montferrato, aunque con algunos leves cambios de diseño, que se aprecian claramente en el anverso.
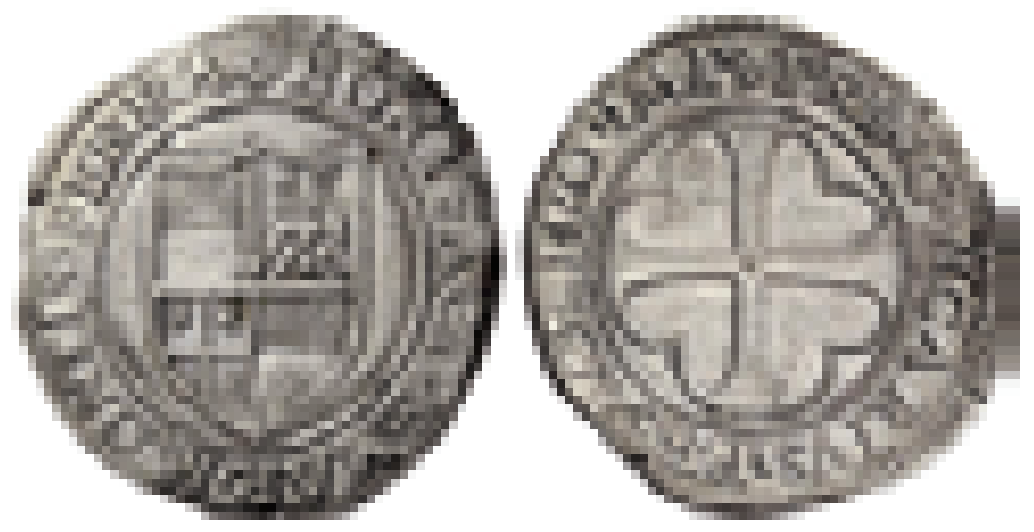

30 Guillermo IX se había casado en 1508 con Anne, Dame de la Guerche, que era hija de René de Valois, Duque de Alençon, y de Margarita de Lorena-Vaudemont (hija de Federico VI de Vaudemont y de Yolanda de Lorena, siendo esta última hija del famoso René de Anjou, duque de Lorena y Bar, rey titular de Nápoles, Jerusalén, etc.). En la leyenda de estas monedas se aprecian sus títulos: Marchio Montferrati Sacri Romani Imperii Princeps Vicarius Perpetuus. 


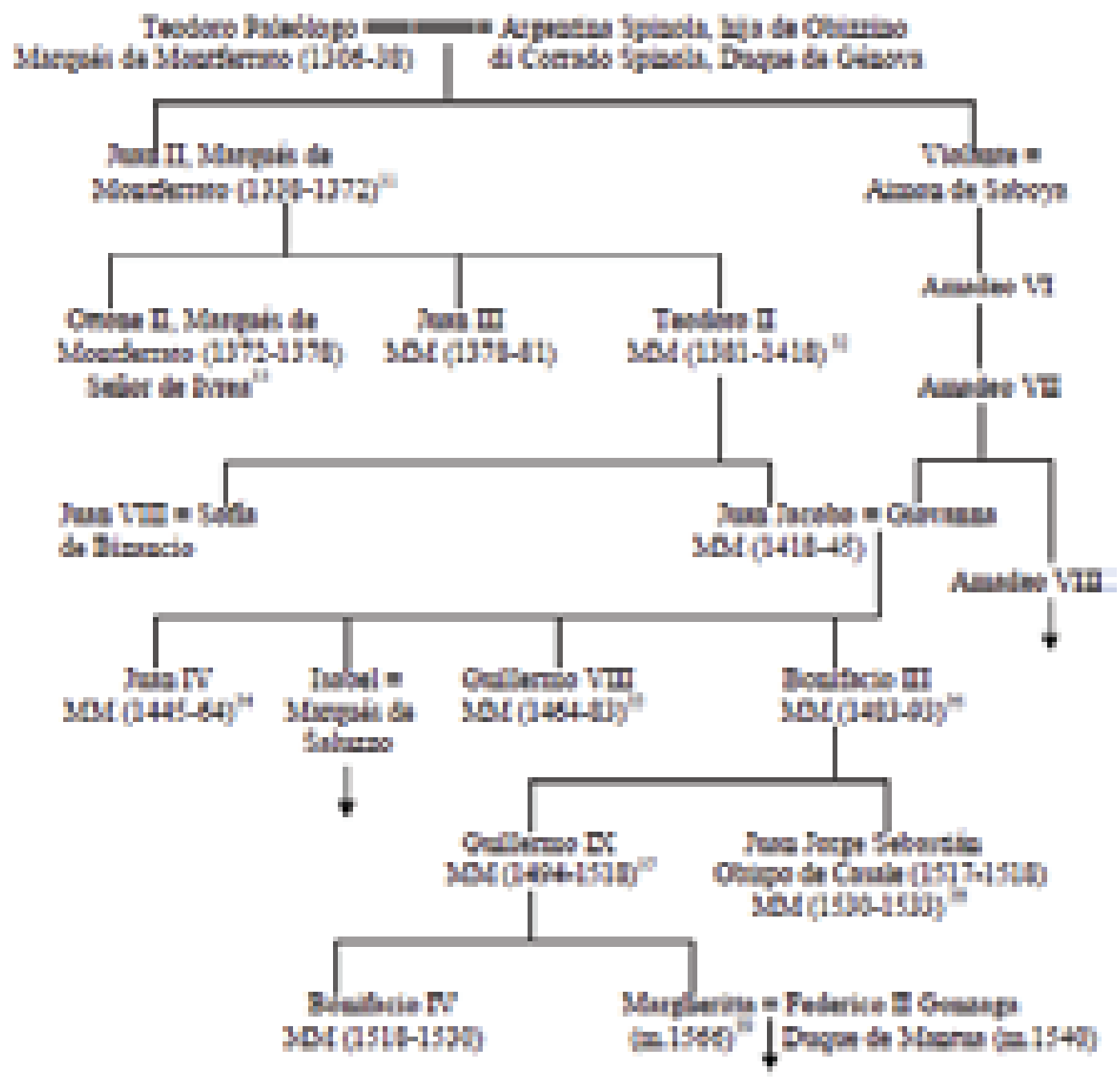

31 Señor de Asti (1339-40, 1356-60, 1361-72), Señor de Novara (1356-58), Vicario Imperial (1355), casado con Cecile de Comminges (1337) y en segundas nupcias con Isabel de Aragón-Mallorca (1358).

32 Capitán General de Génova (1409-13), Señor de Savona (1409-13), Vicario Imperial en Italia, casado con Argentina Malaspina di Lunigiani (m.1387); en segundas nupcias(1393) con Joana de Bar (m.1402) y en terceras (1403) con Margherita de Acaia (m.1464).

33 Casó (1377) con Violante Visconti (m.1376), hija de Galeazzo II señor de Milán.

34 Conde de Acqui (1418-1445) casó (1458) con Margarita de Saboya (m.1483/85). Su único descendiente legítimo fue Helena (m.1496), casada con el duque Viktorin II de Munstenberg

35 Casó (1465) con María de Foix; con (1469) Elisabetta María Sforza y con (1474) Jeanne Bernardin de Brosse. Sólo tuvo hijas, Giovanna, casada con Ludovico del Vasto, Marqués de Saluzzo; Lucrezia, con Gian Bartolomeo del Carreto, y Reinaldo d'Este; y Bianca, con el Duque Carlos I de Saboya.

${ }^{36}$ Casó (1470) con Orvietana de Campo-Fregoso; con (1483) Helena de Brosse-Penthievre; y con (1485) Marija Kantakuzaina Brankovic de Raska.

37 Casó (1508) con Anne de Valois-Alencon, Dame de La Guerche.

38 Abad de Lucedio (1507-18), Obispo de Casale, casó (1533) con Giulia de Aragón, hija del rey Federico IV de Nápoles.

39 La primera hija de Guillermo IX, María, estuvo prometida a Federico Gonzaga, pero se hizo monja; y el novio pasó a casarse con la segunda hija, Margarita, que se convirtió en la heredera de Montferrato tras muchas luchas con sus vecinos, en especial los Duques de Saboya (descendientes de Teodoro I), y los Saluzzo, siendo confirmada la herencia de este estado por decreto imperial de Carlos V. 
A la muerte de Bonifacio IV se produjo en el Montferrato una grave crisis sucesoria, ya que hasta ese momento las mujeres habían estado excluidas de la sucesión y el único varón vivo de la familia era su tío, Juan Jorge, Obispo de Casale, y a su muerte (1533) la herencia debía seguir la línea femenina, siendo reivindicada por los Duques de Saboya, los Marqueses de Saluzzo, y sobre todo por el marido de Margherita, la hermana de Bonifacio IV, Federico II Gonzaga, marqués y luego duque (1530) de Mantua. Las tropas imperiales de Carlos V ocuparon el marquesado (1533) para evitar un conflicto armado entre los pretendientes y al final el Emperador decidió entregar el territorio a Margherita (1536), quedando por tanto unido a los Gonzaga de Mantua, que años después modificaron sus armas ${ }^{40}$ por ello (en época de Guillermo Gonzaga Paleólogo, Duque de Mantua en 1550, Marqués y luego I Duque de Montferrato en 1574, muerto en 1587) incluyendo en el escusón toda la heráldica que hemos visto anteriormente presente en la moneda de Guillermo IX Paleólogo.
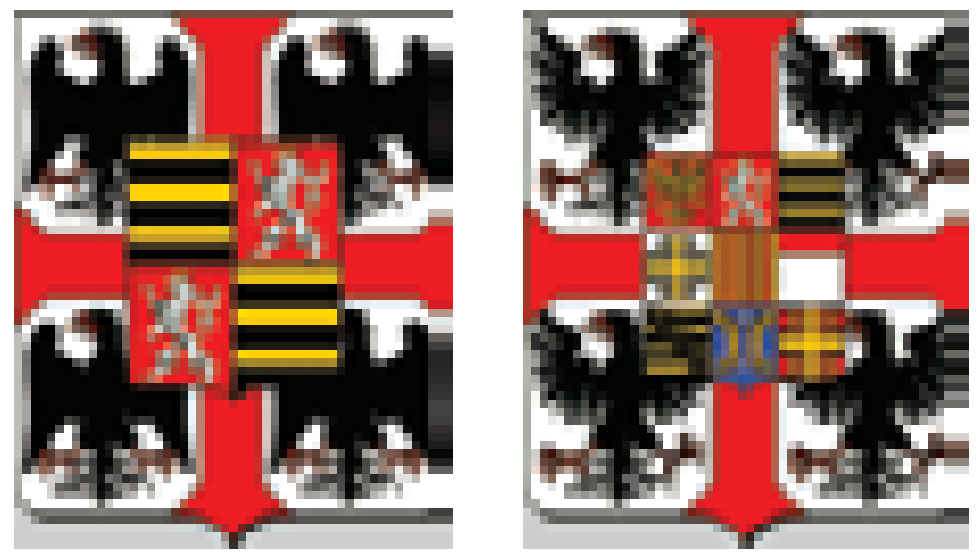

Tras la temprana muerte de Federico II Gonzaga (1540) le sucedió en Mantua y Montferrato su hijo mayor Francisco III, al principio bajo la regencia de su madre, había nacido en 1533. A su muerte sin herederos (1550) le sucedió su hermano Guillermo I (nacido en 1538), volviendo su madre a la regencia. Años después Guillermo consiguió que el emperador Maximiliano II (su cuñado $)^{41}$ elevara el antiguo marquesado de Montferrato a ducado (1574).

Ahora bien, mientras Mantua pasó por herencia a sus dos hijos, Montferrato permanecería (al menos en teoría) en manos de su heredera legal, Margherita Paleólogo, hasta su muerte en 1566, independientemente de que no ejerciera el poder de forma regular, pero este hecho legal queda claro en sus acuñaciones, ya que desde 1536 hasta su muerte las monedas del marquesado llevarían siempre su nombre, acompañado sucesivamente del de su marido y el de sus dos hijos, como puede verse en distintas acuñaciones. Primero veremos dos piezas de plata, en concreto

40 Compuestas en origen por el cuartelado de Gonzaga y el reino de Bohemia, por concesión del rey Wenceslao IV de Luxemburgo, rey de Bohemia y Emperador, a Francisco Gonzaga, capitán de Mantua (1394).Cuando en 1432 el Emperador Segismundo de Luxemburgo nombró a Juan Francisco Gonzaga como Marqués de Mantua este cuartelado se colocó sobre un nuevo diseño heráldico, donde en campo de plata una cruz patada de gules lo divide en cuatro cantones ocupados por águilas de sable. Cuando Guillermo I se convirtió en Duque de Montferrato reemplazó el original cuartelado de Gonzaga y Bohemia por otro más complejo donde incluyó las armas de los Paleólogo de Montferrato ya comentadas al hablar de sus monedas, el águila del Imperio de Oriente, la Cruz de Jerusalén, las Barras de Aragón, Montferrato, Sajonia, Bar y Paleólogo de Constantinopla, mostrando así la definitiva unión de los dos territorios bajo el gobierno de los GonzagaPaleólogo, que no se produjo hasta la muerte de su madre (1566).

${ }^{41}$ Los dos hijos de Margherita se casaron con hijas del Emperador Fernando I y su esposa Ana Jagellón, reina de Bohemia y Hungría. El primogénito, Francisco III, lo hizo con Catalina (en 1549); y el segundo, Guillermo I, con Eleonor (en 1561). 
los llamados testones, que nos muestran a Margherita con sus hijos, todavía menores de edad, la primera con Francisco (donde el retrato de cada uno ocupa una cara de la moneda), utilizando ambos la misma titulación en singular, duque de Mantua y Marqueses de Montferrato; y la segunda la muestra con su hijo menor, Guillermo, donde en anverso aparece el retrato de ambos acolado, mientras en reverso están los escudos de armas de los dos territorios por separado, unidos bajo una corona, mientras que la leyenda une los nombres de ambos, seguidos de sus títulos en plural (duques y marqueses), al que se añade la fecha de la emisión (1553).
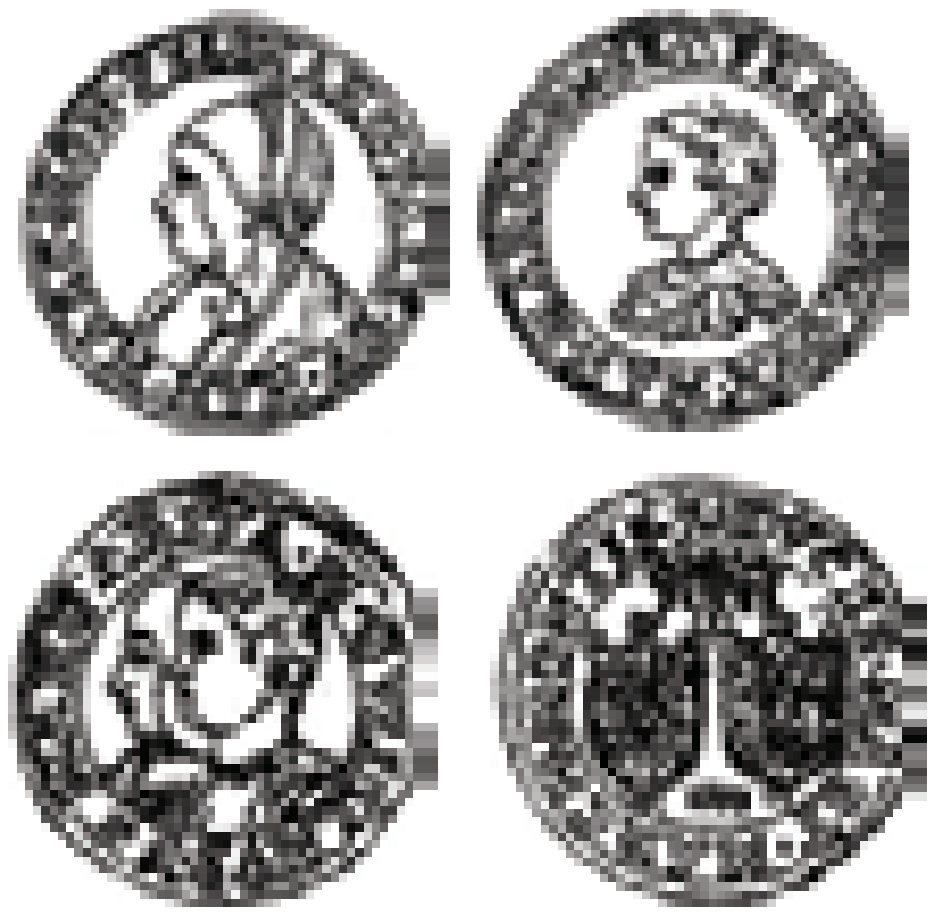

Esta situación se mantuvo tras alcanzar la mayoría de edad su hijo, como puede verse en estas piezas acuñadas durante el gobierno de su hijo Guillermo, en fechas tan tardías como son 1563 y 1565 (apenas un año antes de la muerte de Margherita) donde se mantienen los nombres de ambos (MAR ET GVL) seguidos de sus títulos como Duques de Mantua y Marqueses de Montferrato. Además se aprecia un paso significativo en la unión de ambos territorios, al colocar sus armas en un único escudo, donde aparecen las de los Gonzaga de Mantua y las los Paleólogo de Montferrato, aunque sin llegar a mezclarse ${ }^{42}$.
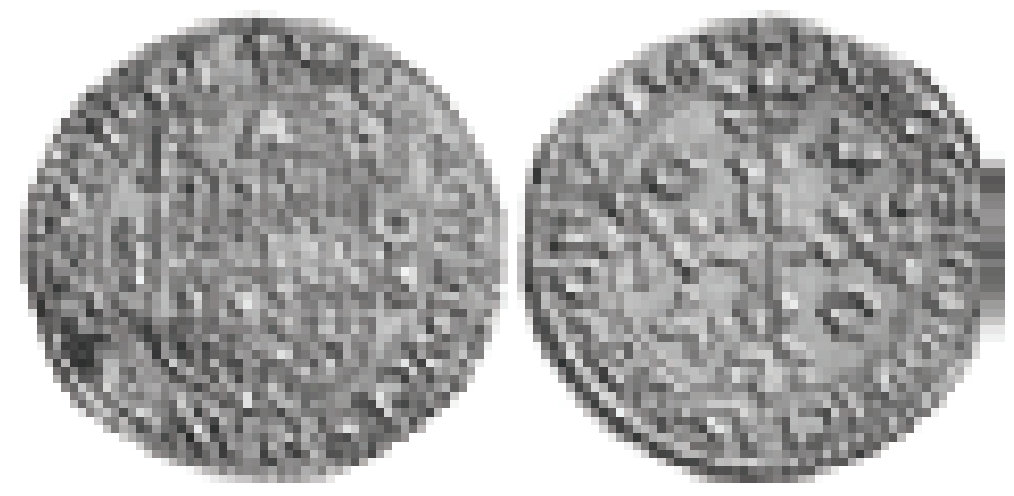

42 Todas las Monedas de los Marqueses de Montferrato pueden verse en el D. PROMIS: Monete dei Paleologi di Montferrato, Torino, 1858; y por supuesto en el Corpus Nummorum Italicorum (CNI), tomo II. 

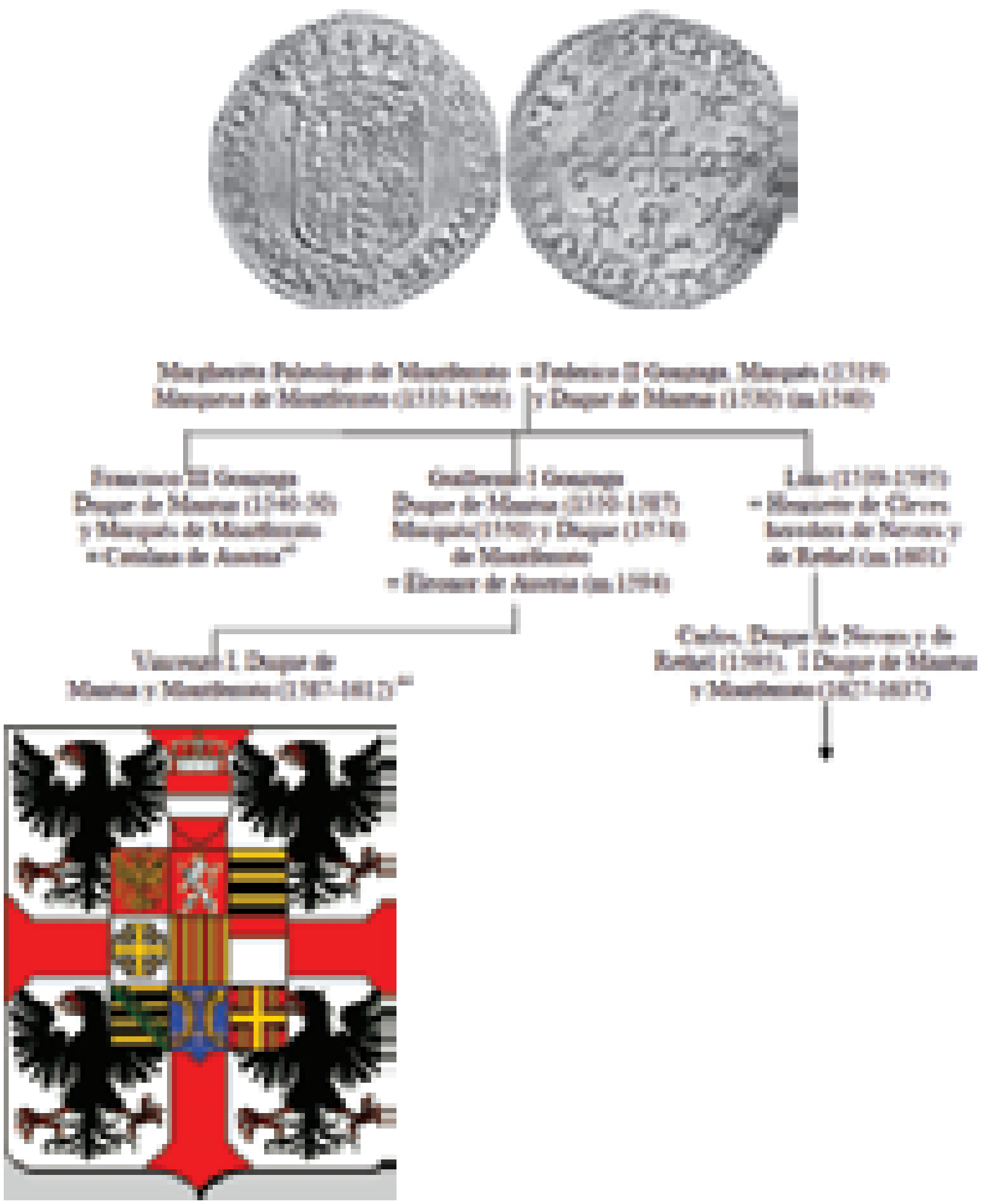

43 A la muerte de Francisco III su viuda volvió a casarse (1553), esta vez con Segismundo II Augusto Jagellón, rey de Polonia, que a su vez había estado casado con Isabel de Austria, su hermana mayor.

44 La última modificación a las armas de los Gonzaga tuvo lugar en este momento, al añadir un escusón de Austria bajo bonete archiducal en el jefe del escudo, indicando que Vincenzo era descendiente de la Casa de Austria a través de su madre. A la muerte de Vincenzo le sucedieron sus tres hijos, Francisco IV (1612) y los cardenales Fernando I (1612-1626) y Vincenzo II (1626-1627), así se extinguió la línea mayor de los Gonzaga, pasando la herencia Mantua-Montferrato a los Gonzaga-Nevers. 